ISSN: 0514-7336

DOI: http://dx.doi.org/10.14201/zephyrus20147489115

\title{
¿HUESOS EN LA BASURA O DEPÓSITO RITUALIZADO? LOS PERROS DESCUARTIZADOS DE LA HUELGA (DUEÑAS, PALENCIA)
}

\section{Bones as rubbish or a ritualized deposit? Dog butchering in La Huelga (Dueñas, Palencia)}

\author{
Corina Liesau von Lettow-Vorbeck*, Ángel Esparza Arroyo** y Alejandra Sánchez Polo*** \\ * Dpto. de Prehistoria y Arqueología. Facultad de Filosofía y Letras-UAM. Avda. Tomás y Valiente, 1. Campus de \\ Cantoblanco. 28049 Madrid. Correo-e: corina.liesau@uam.es \\ ** Dpto. de Prehistoria, Historia Antigua y Arqueología. Facultad de Geografía e Historia. C/ Cervantes, s/n. \\ 37002 Salamanca. Correo-e: esparza@usal.es \\ *** Instituto Nacional de Patrimonio Cultural. Avenida Cristóbal Colón. Quito (Ecuador). Correo-e: alejandra. \\ sanchez@inpc.gob.ec
}

Recepción: 22/01/2014; Revisión: 26/02/2014; Aceptación: 20/06/2014

BIBLID [0514-7336 (2014) LXXIV, julio-diciembre; 89-115]

Resumen: La realización de excavaciones de gran escala en 'campos de hoyos' desde los años 90 del siglo pasado ha ido deparando con cierta frecuencia la aparición de depósitos con restos de fauna articulados, entre ellos, algunos de perros. En este trabajo se estudia uno de tales depósitos, datado por las cerámicas más recientes del relleno del hoyo en la fase Protocogotas I -Bronce medio de la Meseta-y por el $\mathrm{C}^{14}$ en $3350 \pm 30 \mathrm{BP}$, que contenía los restos de dos perros sometidos a una exhaustiva desarticulación y despiece, acompañados por piezas óseas de vacuno. Se presenta el estudio completo de los materiales recuperados de este hoyo de cara a la interpretación de su significado y se examinan también posibles referentes etnográficos e históricos de actividades relacionadas con diferentes tipos de sacrificios donde los canes son los principales protagonistas. Se plantea también su encuadre con otras prácticas simbólicas en las que interviene el perro durante las Edades del Cobre y del Bronce de la Meseta. Poco frecuentes, aunque no excepcionales, los depósitos con restos articulados de fauna requieren de unas técnicas de excavación y registro análogas a las que se emplean con las sepulturas humanas, en orden a posibilitar un estudio posterior riguroso, imprescindible para avanzar en la investigación de estas sociedades prehistóricas de la Edad del Bronce en las que la muerte de ciertos animales -la muerte en general- desempeńa un papel relevante en lo ideológico.

Palabras clave: Depósito de perros; Ritual; Sacrificios; Protocogotas I; Bronce medio; Península Ibérica.

АвSTRACT: Since the last decade of the twentieth century, and thanks to open area excavations that had taken place in pit sites, afforded us some structured depositions containing articulated faunal remains, dogs among them. This paper studies one of these animal deposits which is dated by means of the most recent pottery of the pit filling as Protocogotas I -Middle Bronze Age in the Iberian plateau- as well as radiocarbon dating $3350 \pm 30 \mathrm{BP}$. The results of the above said study revealed that those dogs underwent an exhaustive disarticulation and butchering processes as well as appearing accompanied by some pieces of cattle bones. This paper presents a study of the 
recovered artifacts and faunal remains and the interpretation not only of this singular context but also discuss ethnographical and historical referents of activities related to different types of sacrifices in which dogs played the main role. It was also taken into consideration other symbolic practices performed during the Chalcolithic and the Bronze Age in the Iberian plateau in which dogs are involved. Deposits containing articulated faunal remains are rare but not exceptional and require excavation and registers techniques similar to those used for human burials, in order to perform a later rigorous study, unavoidable for getting forward in further research about Bronze Age societies in which animals' death, and death in general, played a relevant ideological role.

Key words: Structured deposition of dogs; Ritual; Sacrifices; Protocogotas I; Iberian Middle Bronze Age.

\section{Presentación ${ }^{1}$}

En las últimas décadas se han dado a conocer en el ámbito peninsular numerosos depósitos con restos articulados de fauna que presentan unas características un tanto singulares documentados entre otras estructuras domésticas en los poblados denominados 'campos de hoyos' del Neolítico final, Calcolítico o de la Edad del Bronce (Lizcano et al., 1991-92; Bellido, 1996; Palomino et al., 1999; Liesau et al., 2004; 2008: 106; Márquez, 2006; Liesau y Blasco, 2006; Albizuri, 2011; Liesau, 2012) ${ }^{2}$. Del mismo modo, no son ajenos al grupo de Cogotas I

1 Este trabajo se ha realizado dentro del Proyecto Nuevos hallazgos y nuevas perspectivas en el estudio de los restos humanos del Grupo Cogotas I (HAR 2009-10105), financiado por el Plan Nacional I + D del Ministerio de Ciencia e Innovación y del Proyecto Las sociedades calcoliticas y su marco temporal en la región de Madrid. Una revisión a la luz de nuevos datos (HAR 2011-28731) financiado por el Plan Nacional I + D + i del Ministerio de Economía y Competitividad. Agradecemos a la Junta de Castilla y León el permiso para trabajar con los materiales del Museo de Palencia; al director del mismo, J. J. Fernández González, que facilitó toda nuestra labor, y a F. J. Pérez Rodríguez, conservador del Museo y en su día miembro del equipo de trabajo en el yacimiento, la enorme ayuda prestada; a A. Morales Muñiz por sus valiosos comentarios y apreciaciones al texto; a Á. Rodríguez González, autor de los dibujos del material cerámico; a Strato Gabinete Arqueológico, que realizó las excavaciones y rescató la arqueofauna, por las facilidades concedidas; a S. Albizuri Canadell por su asesoramiento en el estudio de las deformaciones en las vértebras lumbares; a E. Martín por su amabilidad en realizar las radiografías del material; y a G. Delibes de Castro por su inestimable colaboración.

2 Cf. también Albizuri, S.: La ofrenda animal durante el Bronce Inicial de Can Roqueta II (Sabadell, Vallès Occidental). Arqueozoología del ritual funerario. Tesis doctoral presentada en 2011 en la Univ. de Gerona [acceso en 02/2014 en http://www.tdx.cat/handle/10803/84118]. los depósitos con restos óseos articulados de animales, a juzgar por las alusiones que a ellos se hacen en publicaciones e informes de excavación. En cambio, no es tan habitual su estudio de forma exhaustiva, cuando resulta imprescindible para abordar alguna hipótesis en torno a unas posibles conductas simbólicas que, desde luego, no son menos interesantes que las de los enterramientos humanos. Con el propósito de contribuir al conocimiento de tales aspectos y aprovechando el marco de un proyecto de investigación ad hoc se ha procedido a revisar algunos viejos hallazgos, entre ellos el que aquí se presenta, procedente de un gran yacimiento palentino, donde se hallaron unos restos que en su día no pudieron ser objeto de una atención que, como se verá, merecían sobradamente.

\section{El yacimiento de La Huelga}

El yacimiento de La Huelga, dado a conocer en la última década del pasado siglo (Misiego et al., 1992; Pérez Rodríguez et al., 1994), se sitúa ${ }^{3}$ en la vega del Pisuerga, en su orilla izquierda, muy cerca del punto donde este río recibe al Carrión. Por su carácter prácticamente llano contrasta con el otro yacimiento coetáneo existente en la misma localidad de Dueñas, el de Pico Castro, que domina desde su imponente altura la orilla contraria del Pisuerga (Fig. 1в). Con una notable extensión, de unas 28 ha, y emplazado sobre la segunda terraza del río, dominando también una fértil zona más baja, posiblemente un meandro abandonado, el pago de La Huelga fue objeto de una intensa explotación de graveras. Por este motivo, a

3 Su posición en las Hojas 311 y 312 del MTNE es aprox. $41^{\circ} 53^{\prime} 05^{\prime} \mathrm{N}, 04^{\circ} 31^{\prime} 16^{\prime}$ w, siendo las coordenadas UTM, referidas al ETRs89, x: 374173.01; y: 4637900.99. 

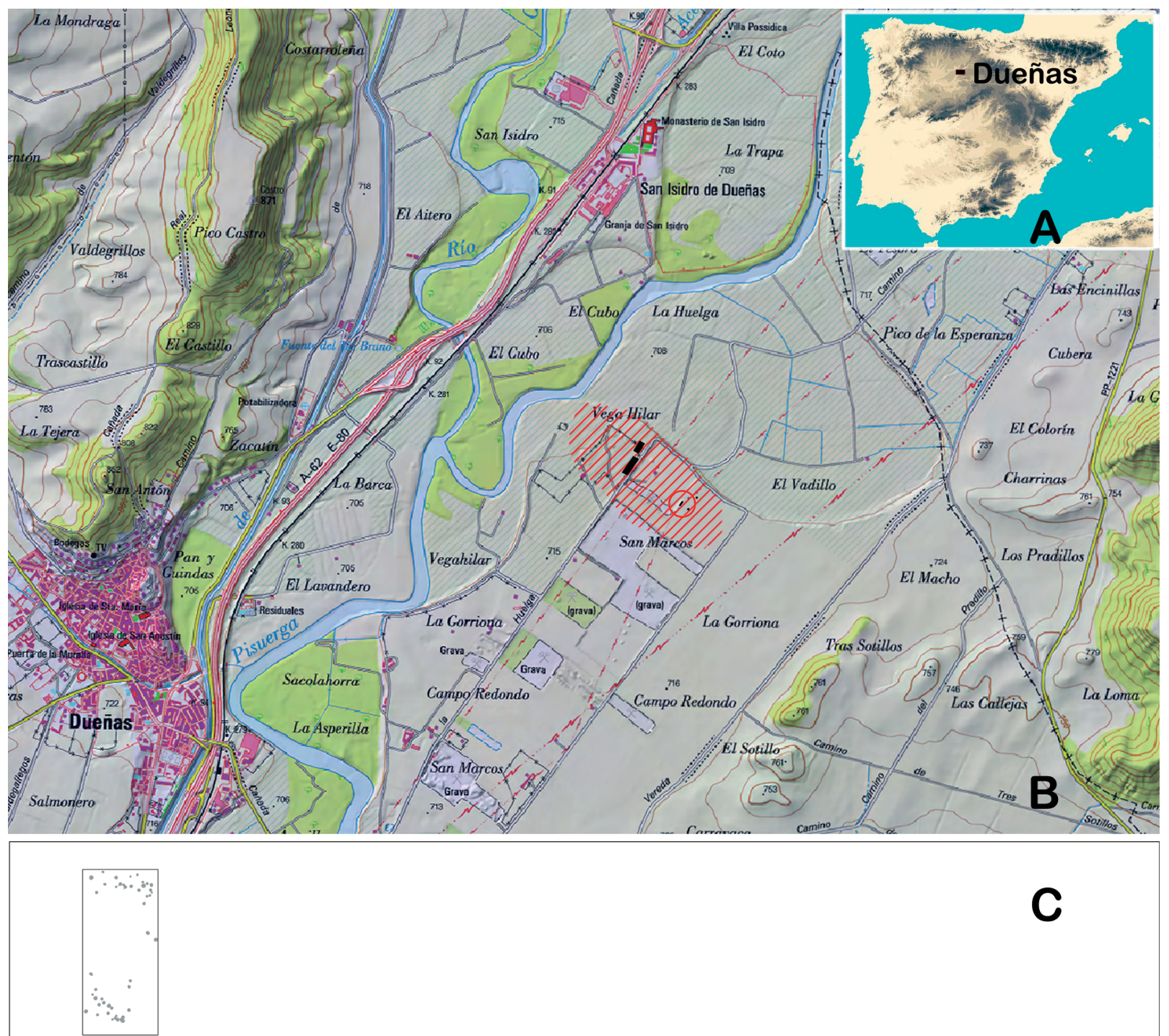

C

\section{Sector 1}
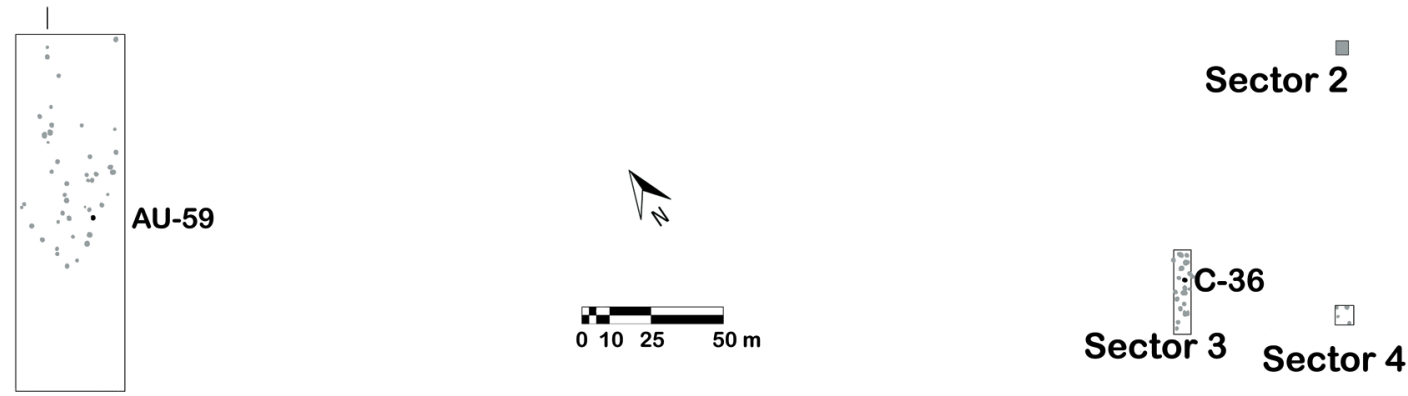

FIG. 1. A) situación peninsular de Dueñas, Palencia; B) localización del yacimiento de La Huelga, rayado y con la situación de las áreas de excavación; C) plano general de los sectores excavados con la ubicación de los depósitos faunisticos 36-C y AU-59 (a partir de Pérez Rodríguez et al., 1994: fig. 10). 


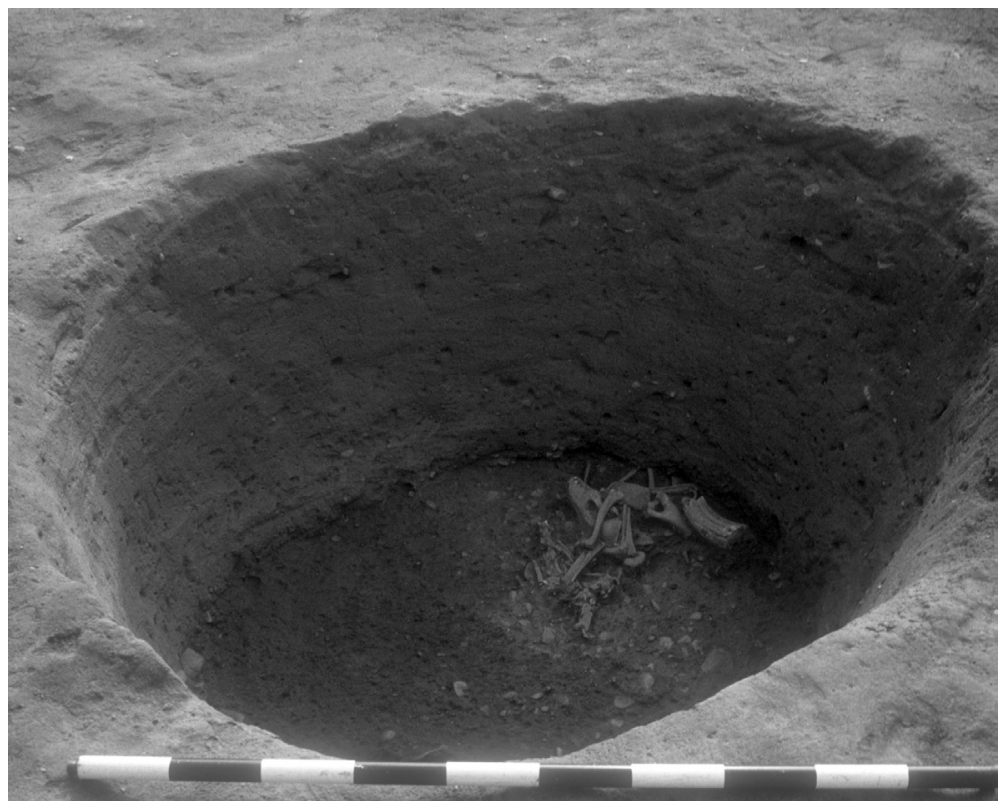

Fig. 2. Fotografía del hoyo 36-C mostrando el depósito de fauna y el espacio vacio en el fondo (cortesía de Strato).

comienzos de los años 90 hubieron de efectuarse hasta cinco campañas de excavación ${ }^{4}$ que pusieron al descubierto un centenar largo de estructuras subterráneas y una notable cantidad de materiales, asignables a diversas ocupaciones escalonadas entre la Edad del Cobre y el Bronce tardío. Aunque parece haber una clara zonificación, con sectores asignables a las distintas etapas, en el sector 3 (Fig. 1C), donde se produjo el hallazgo objeto de este trabajo, se documentó de forma reiterada una mezcla de materiales campaniformes y Protocogotas I, que los excavadores justificaron por barridos en relación con sucesivas ocupaciones o por las periódicas crecidas de Pisuerga (ibid., 1994: 20). Esa incidencia de procesos postdeposicionales conlleva la necesidad de la mayor exigencia con la datación de los rellenos, paso previo a su interpretación en términos culturales.

4 De las memorias de las campañas llevadas a cabo en el yacimiento, interesa ahora: Strato (1992a): Excavación arqueológica en el yacimiento de 'La Huelga' (Dueñas, Palencia). Parcela n..$^{\circ}$, Polígono 5 de Dueñas (IRYDA). Informe técnico depositado en el Servicio Territorial de Cultura (JcyL) de Palencia.

\section{El hoyo 36-C}

Durante la campaña del verano de 1992 se excavó en la parcela 45 del polígono 5 una amplia zanja de 125 $\mathrm{m}^{2}$ que puso al descubierto un total de diecisiete estructuras subterráneas, cuyos materiales pertenecían, lo mismo que los hallados en las zonas que habían ido desmantelando las máquinas de la gravera, al Campaniforme Ciempozuelos y al Protocogotas I.

Uno de tales hoyos, el 36-c, excavado en el terreno arcilloso, no desentonaba de los restantes hallados en el yacimiento, ni por sus características morfológicas - planta paracircular, sección casi cilíndrica, de $77 \mathrm{~cm}$ de profundidad conservada y $141-165 \mathrm{~cm}$ de diámetros $\mathrm{N} / \mathrm{s}$ y $\mathrm{E} / \mathrm{W}$ respectivamenteni por su relleno, el habitual de color grisáceo y textura cenicienta, que contenía algunos fragmentos cerámicos, media docena de lascas de sílex, huesos de fauna, morceñas carbonosas, etc. Pero en esta ocasión, ese relleno superior dio paso a otro de carácter más compacto, arcilloso, que colmataba los últimos $20 \mathrm{~cm}$ del hoyo, cuya base había llegado a recortar el estrato de grava infrayacente al de arcilla. También en este relleno inferior había algunos fragmentos cerámicos, pero lo más destacable fue el hallazgo de un conjunto de restos de fauna, sobre el fondo de grava, en la zona noreste del hoyo (Fig. 2). Aunque aparentemente desordenados, según el informe arqueológico, los huesos parecían corresponder al esqueleto de un cánido que habría sido tirado al fondo, junto a la pared, acompańado de un cuerno de bóvido y otro hueso suelto 5 .

5 Strato (1992a): Excavación arqueológica en el yacimiento de 'La Huelga' (Dueñas, Palencia). Parcela no 45, Polígono 5 de Dueñas (IRYDA). Propiedad de Áridos García $S . A$. Informe técnico depositado en el Servicio Territorial de Cultura (JCyL) de Palencia; Strato (1992b): Lavado, siglado $e$ inventariado de materiales procedentes de la excavación arqueológica del yacimiento de 'La Huelga' (Dueñas, Palencia). Parcela $n{ }^{\circ}$ 45, Polígono 5. Primera intervención arqueológica. Junio 1992. Informe técnico depositado en la Unidad Central de Archivos de la Jcyl. Los materiales se conservan en el Museo de Palencia, con la ref. ${ }^{\text {a }} 92 / 2 / \mathrm{B} / 36-\mathrm{C} / \mathrm{n}$. $^{\text {os }} 1-30$, referencia que se sigue en la numeración de la Fig. 3. 


\section{La cronología del depósito}

A la vista del Inventario de Materiales de la excavación, donde se explicita la atribución de un buen número de fragmentos cerámicos de este hoyo al Campaniforme, se habría asignado esta cronología al depósito faunístico. Una decisión poco discutible, de entrada, toda vez que dichos materiales -11 fragmentos de vasos y cuencos, tal vez también de cazuelas, decorados como se refleja en la Fig. 3A con los motivos propios del Campaniforme de la Meseta (costuras verticales, triángulos rellenos de trazos incisos, zigzags, chevrons, series de metopas y triglifos, incluso una pieza con decoración interior)- se concentraban, además, en el relleno superior del hoyo. Y una decisión que no dejaría de ganar credibilidad al recordar cómo se han multiplicado en los últimos ańos y en muy distintos puntos de la Península Ibérica los hallazgos de enterramientos de perros en contextos calcolíticos (Liesau et al., 2008: 106; Daza, 2011; Liesau, 2012).

Sin embargo, y tras una exhaustiva revisión del material, las cosas resultan muy diferentes. En efecto, dejando a un lado el lote formado por fragmentos de bordes lisos y un par de fondos, todos ellos poco característicos (Fig. 3B, n. ${ }^{\text {os } 5-14 ~ y ~ 28-29), ~ y ~ l o s ~ c i t a-~}$ dos fragmentos campaniformes, lo cierto es que en el conjunto hay también otros fragmentos que, aunque no son totalmente inequívocos, parecen apuntar hacia etapas postcampaniformes (Fig. 3c): por ejemplo, el n. ${ }^{\circ} 26$, de superficie bruñida y en cuya carena hay una serie de trazos oblicuos incisos; o el n. ${ }^{\circ} 15$, con cordones aplicados lisos que debían de formar parte de uno de esos complejos temas, a veces de carácter figurativo, tan comunes en las producciones normeseteńas del Bronce antiguo y medio ${ }^{6}$. En cambio, para el vaso de boca muy cerrada con un tratamiento de trazos oblicuos casi paralelos que produce un característico aspecto rugoso (Fig. 3B, n. ${ }^{\circ}$ 6), sin duda intencional, aunque no conocemos paralelo exacto, podría ir en la línea de algunos recipientes hallados en el yacimiento soriano de Los Tolmos ${ }^{7}$.

Mayor seguridad cronológica aportan los n. ${ }^{\text {s }}$ 2 y 4 (Fig. 3c), también bruñidos, ambos con decoración de líneas paralelas de boquique, siendo

6 Sin ir más lejos, hay un fragmento con guirnalda del propio yacimiento en Misiego et al., 1992: 23, foto central. 242.

Jimeno y Fernández Moreno, 1991: fig. 21, n. ${ }^{\text {ss }} 241$ -

(C) Universidad de Salamanca especialmente interesante el último, pues en él se entrevé una composición de cuadritos sin delimitar formados por líneas paralelas muy apretadas de boquique muy fino, alternando con otros cuadritos lisos, mientras que bajo el labio hay una línea de boquique que se hace triple en el interior del borde. No menos interesante resultan el fragmento n. ${ }^{\circ} 25$ (Fig. 3c), que conserva unos trazos incisos a buen seguro integrados en un tema de triángulos truncados que descienden en disposición radial hacia la base, como puede verse en diversos contextos Protocogotas $\mathrm{I}^{8}$; y el n. ${ }^{\circ} 27$, una cazuela de superficie alisada y con carena baja sobre la que se dispone un zigzag cuyos trazos no convergen, sino que se cortan, todo ello con claros referentes en esa misma fase?. Destacamos que estos dos fragmentos del hoyo tienen sendos paralelos en un mismo hoyo, el 113 de la Fábrica de Ladrillos (Getafe).

En una consideración de conjunto de estos materiales postcampanifomes debería anotarse que si bien algún fragmento podría haber sido considerado antiguo, como el mencionado de la carena baja, lo cierto es que ese detalle, que a veces suele tomarse como indicador del Bronce antiguo, puede verse en cerámicas Protocogotas i por ejemplo en Getafe, en el fragmento antes citado como paralelo por su decoración, y otros vasos del mismo hoyo ${ }^{10}$. Por contra, la presencia de boquique podría hacer pensar en la fase de Plenitud de Cogotas I, pero en el fragmento n. ${ }^{\circ} 4$ el esquema compositivo mantiene total fidelidad al que, realizado con espigas incisas, era probablemente el más característico del Protocogotas I ${ }^{11}$.

8 En el hoyo 113 de la Fábrica de Ladrillos (Getafe, Madrid): Blasco et al., 2007: fig. 286, n. ${ }^{\circ}$ 212932; en el primer hoyo excavado en el Soto de Tovilla I (Tudela, Valladolid): Rodríguez Marcos, 2008: fig. 6.2; probablemente también en El Cementerio (Quintanilla de Onésimo, Valladolid): ibid.: fig. 70.7 .

9 En la Fábrica de Ladrillos de Getafe: Blasco et al., 2007: fig. 284.5 (hoyo 113) y fig. 311 (hoyo 129); en el Caserío de Perales, también en Getafe: Blasco et al., 1995: fig. 1.3 (hoyo 3, con fauna datada en $3356 \pm 68$ вр); y en el hoyo 35.1 de El Pelambre (Villaornate, León): González Fernández, 2009: 128

10 Blasco et al., 1995: fig. 1.1-3.

11 Por ejemplo, en Las Carrávilas (Ávila): Delibes, 1995: 69, fig. 24; La Plaza (Cogeces del Monte, Valladolid): Rodríguez Marcos, 2008: 81, figs. 34 y 36; Los Tolmos (Caracena, Soria): Jimeno Martínez y Fernández Moreno, 1991: 72, fig. 38; La Corvera (Navamoral de Béjar, Salamanca): Fabián, 1995: fig. 53. 


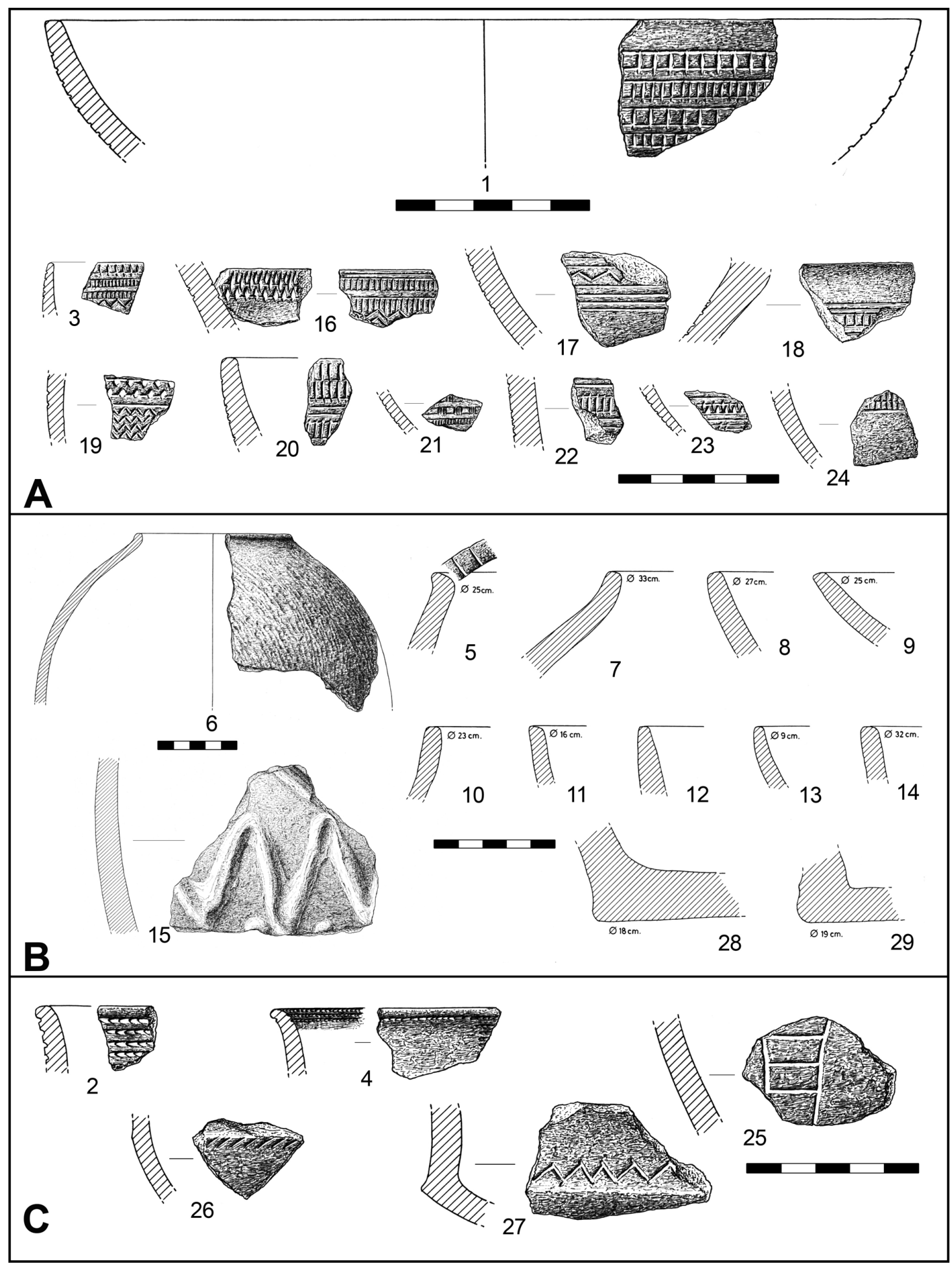

Fig. 3. Material cerámico más significativo: A) Campaniforme; B) de atribución imprecisa; C) Protocogotas I (los números remiten a la sigla del Museo de Palencia, s/n. 5). 
Es importante reseñar que, de acuerdo con el informe de la excavación, el fragmento n. ${ }^{\circ} 4$, con su decoración de boquique, viene del nivel superior, tan rico en fragmentos Ciempozuelos, pero, sobre todo, que el fragmento n. ${ }^{\circ} 27$, de carena baja con zigzag inciso, se halló en el nivel inferior, el que contenía el depósito faunístico.

A la vista de las características del hoyo podrían sugerirse interpretaciones alternativas, pero coincidentes en cuanto a cronología: la primera, que el hoyo, relleno con material campaniforme, fue vaciado y a continuación retallado en su base para

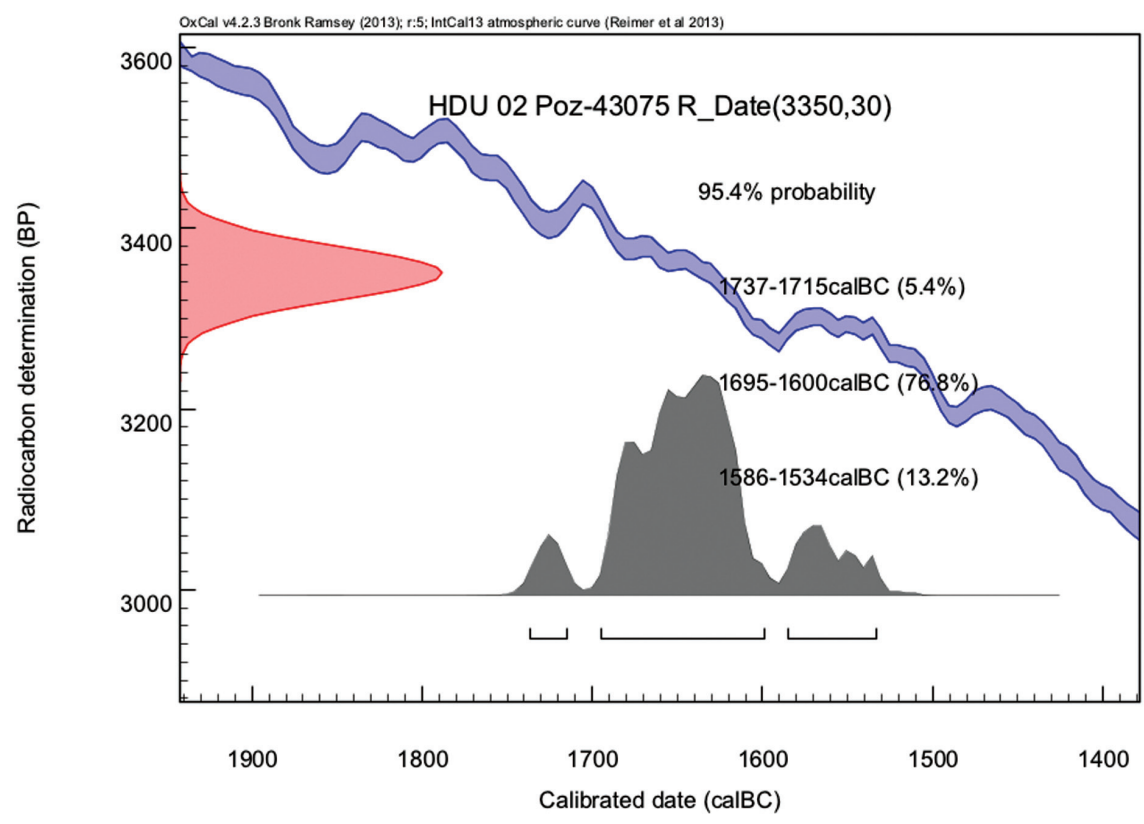
alojar el depósito animalísti-

FIG. 4. Datación radiocarbónica de una muestra del depósito faunistico.

co, que se cubrió después con tierra, incluyéndose entonces fragmentos cerámicos como el n. ${ }^{\circ} 27$, y finalmente se tapó con el sedimento extraído inicialmente, en el que iban fragmentos campaniformes y ahora también Protocogotas. Dado que no hay ninguna evidencia de recorte en las paredes o el fondo del hoyo, cabría considerar más viable una segunda posibilidad: el hoyo, preexistente o hecho para la ocasión, sirvió para depositar la fauna y se rellenó a continuación con tierra de las inmediaciones que contenía materiales heterogéneos. No es fácil argumentar a favor de una tercera eventualidad, la de que en el momento del cierre del hoyo se produjese un aporte premeditado de los fragmentos de estilo Ciempozuelos, recogidos de otro sector cercano al aquí estudiado.

De cualquier modo, y valorando en su conjunto la totalidad de las cerámicas, campaniformes y posteriores, puede proponerse que el depósito de fauna fue realizado en el Bronce medio, siendo colmatado el hoyo por un relleno que, aun conteniendo un conjunto campaniforme muy nutrido, debió de cerrarse en la fase Protocogotas I, tal vez en un momento no temprano de la misma.

En última instancia, además de esa cronología relativa se dispone también de la datación radiocarbónica efectuada en el Poznan Radiocarbon
Laboratory a partir de una muestra de costillas del esqueleto canino depositado en el nivel inferior, que viene a corroborar la propuesta que, como se ha dicho, se desprende del registro arqueológico:

$$
\text { HDU } 02 \quad \text { Poz-43075: } 3350 \pm 30 \text { вР }
$$

A $2 \sigma(95,4 \%)$ : 1737-1715 cal вс $(5,4 \%) ; 1695-1600$ cal вс $(76,8 \%) ; 1586-1534$ cal вс $(13,2 \%)$.

Como puede verse, la calibración, efectuada con el programa OxCal v4.2.3 (curva IntCal 13), conduce a tres intervalos (Fig. 4), siendo el de mayor probabilidad el central, que cubre prácticamente todo el s. XVII a. C. No está de más recordar la datación obtenida en otro hoyo con protagonismo animal, el n. ${ }^{\circ}$ 76-78 del yacimiento madrileńo de la Fábrica de Ladrillos (Getafe), que contenía también material cerámico del Protocogotas I (Liesau et al., 2004). Aquí, el depósito faunístico lo componían principalmente cuartos delanteros y traseros de varias terneras, una de cuyas tibias ha sido datada como Beta-184835: $3340 \pm 70 \mathrm{BP}$, de manera que ambas dataciones constituyen referencias firmes para jalonar la secuencia interna de las manifestaciones simbólicas del grupo Cogotas I. 


\begin{tabular}{|c|c|c|c|c|c|}
\hline \multicolumn{6}{|c|}{ LA HUELGA } \\
\hline Estruct. & NR & TAXÓN & $\begin{array}{l}\text { PESO } \\
(\mathrm{g})\end{array}$ & NMI y edad & DESCRIPCIÓN \\
\hline \multirow{5}{*}{$\begin{array}{l}\text { HOYO } \\
\text { 24-B } \\
\text { Nivel II }\end{array}$} & \multirow{4}{*}{15} & $\begin{array}{l}\text { vacuno } \\
\text { (Bos taurus } \mathrm{L} .)\end{array}$ & 29 & $\begin{array}{l}2: \\
1 \text { ad./senil y } \\
1 \text { inf.-juv. }\end{array}$ & $\begin{array}{l}1 \text { fragm. de } \mathrm{M}^{1} / \mathrm{M}^{2} \text { a falta de raíces }(+++) \text { de adulto/senil } \\
1 \text { fragm. de } \mathrm{P}_{3} / \mathrm{P}_{4}(++) \\
1 \text { fragm. de } \mathrm{M}_{1} / \mathrm{M}_{2}(+)\end{array}$ \\
\hline & & $\begin{array}{l}\text { ovicaprino } \\
\text { (Ovis aries L./Capra } \\
\text { hircus L.) }\end{array}$ & 29 & $\begin{array}{l}2: \\
1 \text { ad. } y \\
1 \text { juv. }\end{array}$ & $\begin{array}{l}1 \text { fragm. de } \mathrm{M}^{3}(++) \mathrm{D} \\
2 \text { fragms. de rama horizontal de mandíbula, } 1 \mathrm{D} \text { con } \\
\text { serie dentaria de leche, } \mathrm{pd}_{4}(++) \mathrm{y}_{1}(+/ 0) \text {; juvenil, } \\
\quad(3-6 \text { meses). Otro fragmento de rama horizontal s } \\
\text { que parece corresponder al mismo individuo } \\
1 \text { fragm. de diáfisis de radio (inf.-juv.) }\end{array}$ \\
\hline & & \begin{tabular}{|l} 
oveja \\
(Ovis aries L.)
\end{tabular} & 7 & 1 & 1 fragm. de diáfisis de metatarso \\
\hline & & $\begin{array}{l}\text { conejo } \\
\text { (Oryctolagus } \\
\text { cuniculus L.) }\end{array}$ & 8 & 1 & $\begin{array}{l}1 \text { fragm. de diáfisis de húmero } \mathrm{D} / \mathrm{s} \text { ? } \\
2 \text { fragm. de diáfisis de ulna, } 1 \mathrm{~s} \text { y } 1 \mathrm{D} \\
1 \text { fragm. hemipelvis } \mathrm{s} \\
1 \text { fragm. de diáfisis de fémur D } \\
1 \text { fragm. de diáfisis de tibia } \mathrm{D} \\
1 \text { sacro, probablemente todo de un individuo }\end{array}$ \\
\hline & 20 & $\begin{array}{l}\text { sin identificar } \\
\text { Macro } \\
\text { Meso }\end{array}$ & $\begin{array}{l}23 \\
20\end{array}$ & & $\begin{array}{l}\text { Macrofauna: } 5 \text { esquirlas de diáfisis, } 1 \text { con huellas de } \\
\text { combustión (negro) } \\
\text { Mesofauna: } 15: 6 \text { con huellas de combustión ( } 1 \text { marrón } \\
\text { claro; } 4 \text { negros y } 2 \text { calcinados) }\end{array}$ \\
\hline \multirow{5}{*}{$\begin{array}{c}\text { HOYO } \\
\text { C-36 }\end{array}$} & 97 & $\begin{array}{l}\text { perro } \\
\text { (Canis } \\
\text { familiaris L.) }\end{array}$ & 830 & $\begin{array}{l}2: \\
-1 \text { entre } 12- \\
20 \text { meses; } \\
-1 \text { entre } 20- \\
24 \text { meses }\end{array}$ & $\begin{array}{l}\text { cráneo, vértebras cervicales y miembros anteriores } \\
\text { incompletos de } 1 \text { individuo } \\
\text { columna vertebral incompleta y miembros anteriores } \\
\text { incompletos de otro individuo } \\
42 \text { fragms. de costillas sin asignación }\end{array}$ \\
\hline & 3 & $\begin{array}{l}\text { Vacuno } \\
\text { (Bos taurus L.) }\end{array}$ & 427 & 1? juv.-ad. & $\begin{array}{l}1 \text { clavija ósea } \mathrm{D} \text { incompleta } \\
1 \text { mitad distal de húmero } \mathrm{D} \\
1 \text { esquirla de diáfisis de radio }\end{array}$ \\
\hline & 2 & $\begin{array}{l}\text { Ovicaprino } \\
\text { (Ovis aries L./Capra } \\
\text { hircus L.) }\end{array}$ & 13 & 1 ad. & $\begin{array}{l}1 \text { fragm. de } M_{3}(++) \text {, ad. } \\
1 \text { esquirla de diáfisis distal de tibia }\end{array}$ \\
\hline & 1 & \begin{tabular}{|l} 
Suido \\
(Sus sp.)
\end{tabular} & 43 & 1 juv. & $\begin{array}{l}1 \text { fragm. de rama horizontal de mandíbula s con } \mathrm{M}_{2} \\
(+/++) \\
\mathrm{y}_{3}(+) \text {, juv. }\end{array}$ \\
\hline & 50 & $\begin{array}{l}\text { sin identificar } \\
\text { Meso }\end{array}$ & 37 & & $\begin{array}{l}\text { pequeñas esquirlas de diáfisis y fragms. de huesos, } \\
\text { probablemente la mayoría de los esqueletos de los perros }\end{array}$ \\
\hline
\end{tabular}

FIG. 5. Relación del NR, NMI, peso y breve descripción de los restos faunísticos recuperados de los hoyos 24-By 36-C del yacimiento de La Huelga. 


\section{Estudio arqueozoológico ${ }^{12}$ de la fauna del hoyo 36-C}

La fauna del yacimiento de La Huelga fue recuperada pero no ha sido estudiada, excepto la de dos hoyos, el 24-B y el 36-C (Fig. 5). En el primero de ellos, que contenía 35 restos óseos muy fragmentados, solo 15 han podido ser identificados, una cantidad muy reducida para una consideración cuantitativa, y que solamente sirve para ilustrar, como desechos culinarios del yacimiento, algunas de las especies recuperadas habitualmente en 'campos de hoyos' de la Edad del Bronce como son el vacuno (Bos taurus L.), los ovi-

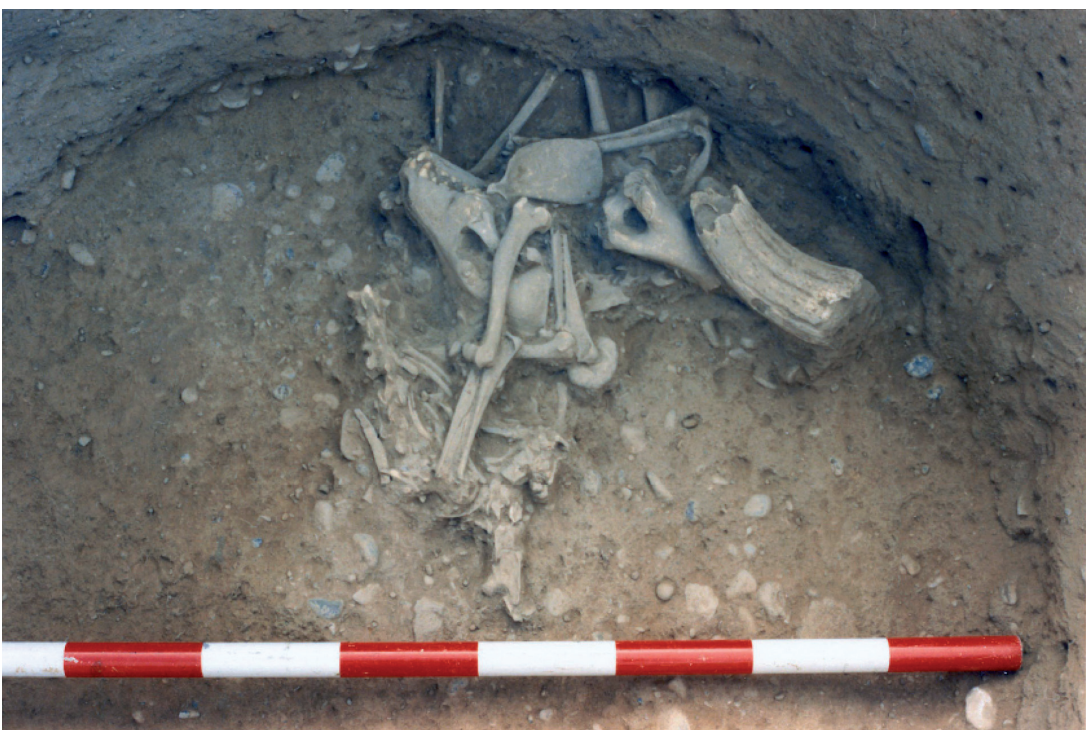

FIG. 6. Fotografía del conjunto faunistico durante el proceso de excavación (imagen cortesía de Strato). caprinos (Ovis aries L.; Capra hircus L.) y el conejo (Oryctolagus cuniculus L.). En el hoyo 36-c, que motiva este artículo, además del conjunto depositado en su base que integraban los restos de dos perros y dos porciones de vacuno, se hallaron también unos pocos elementos dispersos en el relleno -esquirlas óseas y piezas dentarias de suido (Sus sp.) y de ovicaprino-, que como en el caso anterior pueden considerarse desechos alimentarios acumulados en diferentes suelos de ocupación y mezclados posteriormente con el sedimento que colmata la estructura. Puede aludirse, finalmente, al hoyo AU-59 (Misiego et al., 1992: 21), situado a unos $400 \mathrm{~m}$ del anterior, y que contenía un depósito parcial de vacuno, actualmente en estudio.

Abordando el depósito canino objeto de este trabajo, se puede observar en el único documento gráfico

12 La metodología de estudio de los restos faunísticos sigue los criterios expuestos en Morales y Liesau, 1995; Liesau, 1998. Para la determinación de la edad del vacuno se han consultado las tablas de fusión del postcraneal de la Escuela de Múnich, y en el estudio tafonómico se siguen los criterios establecidos en el trabajo de Liesau (1998). En el estudio de los perros se han utilizado para la estimación de la edad en el esqueleto postcraneal Habermehl (1974) y para el craneal, Horard-Herbin (2000), concretamente la sistematización del desgaste dentario; de Harcourt (1974) se toman los datos para el cálculo de la talla a partir de los índices de Koudelka, también discutidos y valorados en Driesch y Boessneck (1974), y la osteometría se basa en los criterios de Driesch (1976). del que se dispone del proceso de la excavación (Fig. 6) que durante el trabajo de campo, aunque exhaustivo y con una buena delimitación del acúmulo de huesos hallados junto a la pared al NE de del hoyo 36-C, no se reconoció inicialmente la compleja naturaleza del hallazgo. Según se desprende de esa Fig. 6 se apreciaba un conjunto formado por dos porciones -clavija ósea y húmero- de vacuno (Bos taurus L.), los cuartos delanteros articulados de un perro (Canis familiaris L.), además de algunas costillas y porciones de un esqueleto axial sin conexión aparente. Pero la fotografía permite ya ver que esos restos de perro cubren parcialmente a otro individuo con cráneo y en posición articulada que yace en un plano inferior (Figs. 6 y 16). Probablemente la ausencia de otro cráneo hizo que no se percibiesen los restos del segundo perro, de manera que en el momento de la extracción se levantaron y se mezclaron todos los huesos, circunstancia que ha causado serias dificultades en asignar las porciones axiales al cráneo como también los respectivos huesos apendiculares.

Del estudio detallado de los restos óseos se desprende la siguiente asignación de porciones anatómicas:

\subsection{El perro.$^{\circ} 1$}

Corresponde a los restos articulados de un perro visibles en un plano inferior de la fotografía. Aunque está cubierto por otros huesos, todo parece 


\begin{tabular}{|c|c|c|c|c|c|}
\hline \multicolumn{3}{|c|}{$\begin{array}{l}\text { Osteometría craneal } \\
\text { del perro n. }{ }^{\circ} 1\end{array}$} & \multicolumn{3}{|c|}{$\begin{array}{l}\text { Osteometría mandibular } \\
\text { del perro } .^{\circ} 1\end{array}$} \\
\hline N. ${ }^{\circ}$ & $\mathrm{s}$ & D & N. ${ }^{\circ}$ & $\mathrm{s}$ & $\mathrm{D}$ \\
\hline 1 & - & - & 1 & - & 120 \\
\hline 2 & - & - & 2 & - & 119,5 \\
\hline 3 & \multicolumn{2}{|l|}{152,9} & 3 & - & 115,9 \\
\hline 4 & - & - & 4 & 108,3 & 106,2 \\
\hline 5 & - & - & 5 & 104,6 & 102,6 \\
\hline 6 & - & - & 6 & - & \\
\hline 7 & \multicolumn{2}{|l|}{87,4} & 7 & 71,6 & 72,2 \\
\hline 8 & - & - & 8 & 65,7 & 65,5 \\
\hline 9 & \multicolumn{2}{|l|}{89} & 9 & 61,6 & 62,4 \\
\hline 10 & - & - & 10 & 32,1 & 33,4 \\
\hline 11 & - & - & 11 & 34,1 & 36,5 \\
\hline 12 & \multicolumn{2}{|l|}{64,2} & 12 & 29,1 & 30,5 \\
\hline 13 & \multicolumn{2}{|l|}{82,5 a) 80,7} & 13 & L: 20,2 B: 7,6 & L: I9, I B: 7,6 \\
\hline 14 & - & - & 14 & I 8,8 & 19,9 \\
\hline $14 a$ & - & - & 15 & L: 8,4 B: 6,2 & L: 8,8 в: 6,2 \\
\hline 15 & 62 & 59,6 & 16 & - & - \\
\hline 16 & 16,4 & - & 17 & 10,9 & 11,1 \\
\hline 17 & 45,7 & (48) & 18 & 49,5 & 49,8 \\
\hline 18 & 18,6 & 16,9 & 19 & 22 & 18,3 \\
\hline $18 \mathrm{a}$ & GB: 8,5 & GB: 8,7 & 20 & 16,9 & 11,3 \\
\hline 19 & 17,9 & & & - & - \\
\hline 20 & L: I I,8 B: I 4, I & L: I I,6 B: I 4,6 & & & \\
\hline 21 & L: 6 в: 9,7 & L: 6, I B: 9,8 & & & - \\
\hline 24 & \multicolumn{2}{|l|}{60,7} & & & - \\
\hline 25 & \multicolumn{2}{|l|}{35,7} & & & \\
\hline 26 & \multicolumn{2}{|l|}{62,2} & & & - \\
\hline 27 & \multicolumn{2}{|l|}{19} & & & - \\
\hline 28 & \multicolumn{2}{|l|}{13,6} & & & \\
\hline 29 & \multicolumn{2}{|l|}{51,3} & & & - \\
\hline 31 & \multicolumn{2}{|l|}{38,9} & & & - \\
\hline 32 & \multicolumn{2}{|l|}{44,4} & & & \\
\hline 33 & \multicolumn{2}{|l|}{31,5} & & & - \\
\hline 34 & \multicolumn{2}{|l|}{32,4} & & & - \\
\hline 36 & \multicolumn{2}{|l|}{32,2} & & & \\
\hline 39 & \multicolumn{2}{|l|}{44,7} & & & - \\
\hline 40 & \multicolumn{2}{|l|}{39} & & & - \\
\hline
\end{tabular}

Fig. 7. Medidas del cráneo del perro n. ${ }^{\circ} 1$ recuperado en el hoyo 36-C, según los criterios establecidos por A. von den Driesch (1976).

indicar que estaba en conexión anatómica, aunque tan solo se han recuperado el cráneo, las siete vértebras cervicales y los cuartos delanteros. Como se puede observar en la Fig. 9 el cráneo del perro y sus primeras vértebras cervicales -algunas de ellas unidas por concreciones- presentan un grado de con- servación aceptable, aunque muchos están cubiertos por concreciones, especialmente el cráneo y su cavidad craneal que están totalmente recubiertos por una capa muy compactada de carbonatos, mientras que la escápula izquierda también presenta fragmentos de costillas y cantillos de río adheridos a su lámina. Sin embargo, los huesos largos se encuentran menos afectados por las concreciones y no se descarta que algunos huesos menores recuperados del conjunto -metacarpianos y falanges- correspondan a la extremidad izquierda de este individuo, aunque por la inseguridad en su asignación se descarta realizar con ellos cálculos para estimar la altura media en la cruz.

En relación con la edad del can, la dentición definitiva está completa ${ }^{13} \mathrm{y}$ el grado de desgaste dentario es muy leve en el protocono del primer molar inferior ${ }^{14}$ por lo que quedaría asignado a una categoría de edad calificada como de animal joven, es decir, de entre 12 y 20 meses de edad. Su corta edad también se refleja en el esqueleto postcraneal, donde los cuerpos vertebrales posteriores todavía no se han fusionado y las epífisis proximales de los húmeros están en trance de fusión. Aunque en este ejemplar resulta arriesgado calcular su alzada, se puede afirmar que, como mínimo, estaría en un rango de entre 46 y $47 \mathrm{~cm}$, teniendo en cuenta que no pudo concluir su fase de crecimiento (Fig. 10).

\subsection{El perro n. ${ }^{\circ} 2$}

Los restos del individuo n. ${ }^{\circ} 2$ aparecen parcialmente desarticulados, a falta del cráneo, algunas vértebras costales y lumbares, como también los cuartos traseros. En las

13 Según Habermehl (1974) esto ocurre a partir de los 6-12 meses de edad.

${ }^{14}$ Sería un estadio de desgaste de "tipo $\mathrm{Ba}$ ", según Horard-Herbin (2000: 117). 
Figs. 6 y 16 se puede reconocer cómo los cuartos delanteros en conexión anatómica cubren parcialmente el cráneo y patas delanteras del perro n. ${ }^{\circ} 1$, y también grupos de vértebras en conexión y costillas, muy probablemente de este individuo, en un plano inferior a los cuartos delanteros. Una vez limpias y colocadas las vértebras y los huesos apendiculares, estos quedan reflejados en la Fig. 9. En general las vértebras presentan escasas alteraciones en superficie, aunque también aquí dos vértebras cervicales están unidas por concreciones. Hay que destacar que parte del esqueleto apendicular muestra algunas fracturas postdeposicionales antiguas en sus porciones distales -radio-ulna-. La secuencia de las vértebras no está completa: las costales son muy escasas y presentan un estado de conservación deficiente, mientras que sí ha sido posible reconstruir la secuencia de las vértebras lumbares, de las que desgraciadamente casi todas presentan fracturas recientes (por extracción) de sus apófisis espinosas excepto una ciertamente deformada, detalle que, como veremos más adelante, es un dato de gran interés. En el conjunto óseo

\begin{tabular}{|c|c|c|c|c|c|}
\hline \multirow{2}{*}{$\begin{array}{c}\begin{array}{c}\text { Porción } \\
\text { anatómica }\end{array} \\
\text { atlas }\end{array}$} & \multirow{2}{*}{\begin{tabular}{|l}
$\begin{array}{c}\text { Medidas según A. von } \\
\text { den Driesch (1976) }\end{array}$ \\
GL
\end{tabular}} & \multicolumn{2}{|c|}{ Perro n. ${ }^{\circ} 1$} & \multicolumn{2}{|c|}{ Perro n.o 2} \\
\hline & & $(31,9)$ & & & \\
\hline & Lad & 15 & & & \\
\hline \multirow[t]{3}{*}{ axis } & LAPa & $((42,6))$ & & $(41,8)$ & \\
\hline & SBV & $(18,4)$ & & $(17,7)$ & \\
\hline & BFCr & 25,6 & & 27,9 & \\
\hline \multirow[t]{7}{*}{ escápula } & $\mathrm{HS}$ & - & 111,4 & 110 & - \\
\hline & DHA & - & 105,6 & - & - \\
\hline & Ld & - & 50,7 & - & - \\
\hline & SLC & 21 & 20,8 & 19,8 & 19,5 \\
\hline & GLP & 26,3 & 25,9 & 25,0 & 25,4 \\
\hline & BG & 15,3 & 15,2 & 15,8 & 15,9 \\
\hline & $s / D$ & $s$ & $\mathrm{D}$ & $s$ & D \\
\hline \multirow[t]{6}{*}{ húmero } & GL & $(144,5)$ & $(145,1)$ & 135,4 & 134,4 \\
\hline & GLC & 139,2 & 139,3 & 130,5 & 130,7 \\
\hline & DP & 35,6 & 35,8 & 35,5 & 35,4 \\
\hline & SD & 11,1 & 11,1 & 11,5 & 11,5 \\
\hline & вd & 27,0 & 26,9 & 28,1 & 28,4 \\
\hline & $S / D$ & $s$ & D & $\mathrm{s}$ & D \\
\hline \multirow[t]{5}{*}{ radio } & GL & - & $(145,5)$ & - & - \\
\hline & вр & - & 16,3 & 16,4 & 16,3 \\
\hline & SD & 10,8 & 10,9 & - & - \\
\hline & вd & 20,9 & 20,9 & - & - \\
\hline & $S / D$ & s & D & $s$ & D \\
\hline \multirow[t]{5}{*}{ ulna } & GL & - & I7I & - & - \\
\hline & SDO & 19,4 & I8,6 & I9,6 & 19,0 \\
\hline & DPA & 22,8 & $2 I, 6$ & 23 & 22,7 \\
\hline & BPC & I3,6 & 13,3 & I5,I & \begin{tabular}{|l|}
4,7 \\
\end{tabular} \\
\hline & $s / D$ & $s$ & D & $s$ & D \\
\hline
\end{tabular}

FIG. 8. Medidas del postcraneal de los dos perros recuperados del hoyo 36-C. recuperado (Fig. 5) tampoco faltan las costillas, pero al estar muy fracturadas y en la imposibilidad de asignarlas a uno de los individuos, no se reflejan en la Fig. 9. De todas formas, la ausencia de gran parte de la columna vertebral, especialmente las costales del can $n .^{\circ} 1$, parece indicar que se corresponden con el perro.$^{\circ} 2$.

En relación con la determinación de la edad se puede avanzar para este perro que, al estar las vértebras fusionadas, tiene una edad mínima de entre los 20-24 meses, aunque su precario estado de conservación ha dificultado la reconstrucción de su secuencia -fracturas antiguas y deformación de algunas piezas, 


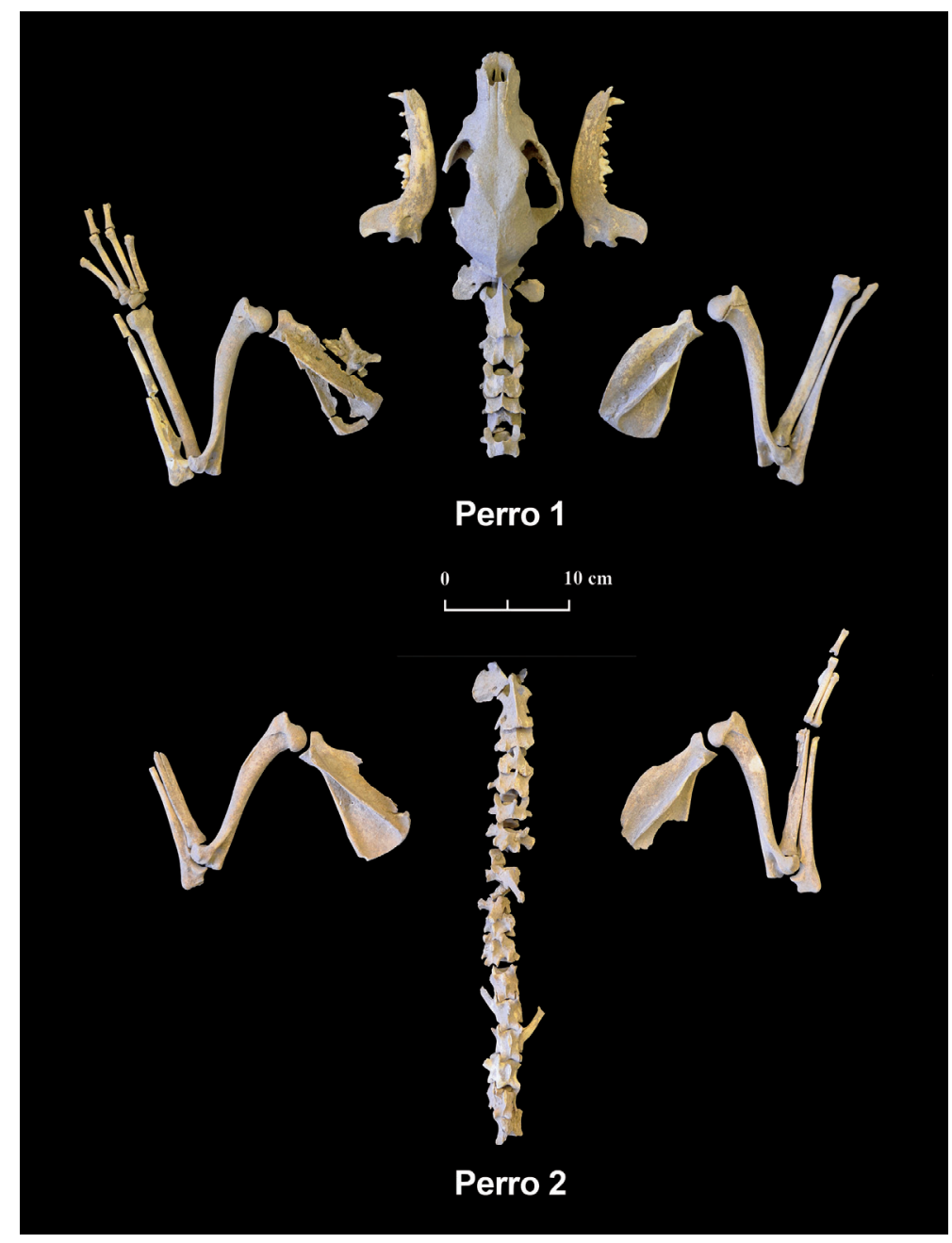

Fig. 9. Propuesta de reconstrucción de los esqueletos parciales de al menos dos perros (Canis familiaris L.) recuperados en el hoyo 36-C de La Huelga (columna vertebral, en norma dorsal; escápula y huesos largos, en norma lateral).

ausencia de apófisis espinosas, transversas etc.-. La recuperación de algunos pocos huesos largos ha permitido hallar la alzada del animal, cuyos valores oscilan entre los 43 a $46 \mathrm{~cm}$; sería, por tanto, de menor talla que el perro n. ${ }^{\circ} 1$ (Fig. 10).

La columna vertebral de este perro no tendría mayor interés en ser estudiada si no fuesen palmarios dos hechos merecedores de un análisis más detallado:

a) Hay al menos 30 huellas antrópicas, algunas de ellas muy contundentes, en numerosas piezas, como una vértebra que presenta seis acciones de percusión ${ }^{15}$. En dos costillas y, sobre todo, en el atlas, axis y otras vértebras cervicales se observan incisiones y muescas (Fig. 11). Las vértebras costales, incompletas y mal conservadas, no permiten extraer mayores conclusiones, sin embargo, en casi todas las vértebras lumbares, las apófisis transversas han sido eliminadas por reiteradas acciones de percusión, como también los cuerpos vertebrales que se han visto muy afectados por numerosas huellas de despiece. Estas aparecen sobre todo en la cara ventral y son el resultado de acciones de percusión tanto en sentido axial, es decir, en el eje de la columna vertebral, como perpendicular o transverso (Fig. 12). En algunos casos los cuerpos vertebrales han sido seccionados, mientras que en otros los impactos del golpe han dejado la impronta del útil en el hueso. La nitidez de dichas huellas y las facetas de seccionado $y$ fracturas en fresco provocadas por una percusión contundente sobre dos vértebras son claros indicios de una actividad de despiece poco tiempo después de la muerte del animal. Las Figs. 12 y 13 muestran un detalle de las diferentes huellas comentadas anteriormente: percusión en sentido axial, transverso y varias fracturas a partir de una acción de percusión, como se observa en la vértebra inferior de la imagen.

b) La deformación de las apófisis espinosas de las vértebras lumbares es otro indicio de gran interés, aunque desgraciadamente solo se dispone de una pieza completa, habiéndose fracturado las demás durante el proceso de excavación y extracción de los esqueletos. En la Fig. 14 se muestran las radiografías ${ }^{16}$ de

15 La terminología empleada en el estudio de las huellas antrópicas sigue los criterios de Liesau (1989).

${ }_{16}$ Radiografías realizadas con un generador Pierotti, mod. 100/100, n. ${ }^{\circ}$ TP036, con una tensión máxima e intensidad máxima de $100 \mathrm{kV} / 100 \mathrm{~mA}$. El tubo emisor es CEI, mod. 105/6 y el equipo de revelado es de tipo digital indirecto, Konica-Minolta, Regius Model 110s. 
las tres vértebras lumbares mejor conservadas: como puede observarse, la apófisis espinosa en la de la izquierda está fracturada en su base; en la del medio está completa, y en la de la derecha, parcialmente conservada. Las dos últimas piezas presentan la particularidad de que la trayectoria de sus apófisis está curvada lateralmente, cuando normalmente forman un ángulo recto con respecto al arco neural. Como en la radiografía no se detecta en la apófisis línea o callo de fractura alguno -indicio de un evento traumáticoni los cuerpos vertebrales o los huesos largos muestran macroscópicamente altera-

\begin{tabular}{|c|c|c|c|c|}
\hline \multirow[t]{2}{*}{ Individuo } & $\begin{array}{l}\text { Porción } \\
\text { anatómica }\end{array}$ & Factor & $\begin{array}{l}\text { AMC } \\
(\mathrm{cm})\end{array}$ & 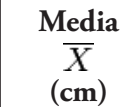 \\
\hline & & Factor según Harcourt (1974) & & \\
\hline \multirow{8}{*}{ perro n. ${ }^{\circ} 1$} & húmero D & $(3,43 x G L)-26,54$ & $(46,9)$ & \multirow{3}{*}{$(47,2)$} \\
\hline & húmero $\mathrm{s}$ & $(3,43 \times \mathrm{xGL})-26,54$ & $(47,1)$ & \\
\hline & radio D & $(3,18 \mathrm{xGL})+19,51$ & $(48,2)$ & \\
\hline & & Factor según Koudelka (1885) & & \\
\hline & húmero D & $3,37 x G L$ & $(48,9)$ & \multirow{3}{*}{$(45,5)$} \\
\hline & húmero $\mathrm{s}$ & $3,32 \times \mathrm{xLL}$ & $(48,6)$ & \\
\hline & radio D & $2,67 \mathrm{xGL}$ & $(38,9)$ & \\
\hline & & Factor según Harcourt (1974) & & \\
\hline \multirow[t]{5}{*}{ perro n. ${ }^{\circ} 2$} & húmero $\mathrm{s}$ & $(3,43 x G L)-26,54$ & 43,8 & \multirow[t]{2}{*}{43,6} \\
\hline & húmero D & $(3,43 x G L)-26,54$ & 43,4 & \\
\hline & & Factor según Koudelka (1885) & & \multirow{3}{*}{45,5} \\
\hline & húmero $\mathrm{s}$ & $3,37 \mathrm{xGL}$ & 45,6 & \\
\hline & húmero D & $3,37 x G L$ & 45,3 & \\
\hline
\end{tabular}

Fig. 10. Cálculo de las alturas medias en la cruz, en función de los huesos largos conservados, según los indices de Harcourt (1974) y de Koudelka (1885). ciones degenerativas o infecciosas detectables — exóstosis,

porosidad, etc.- , se puede descartar que la defor-

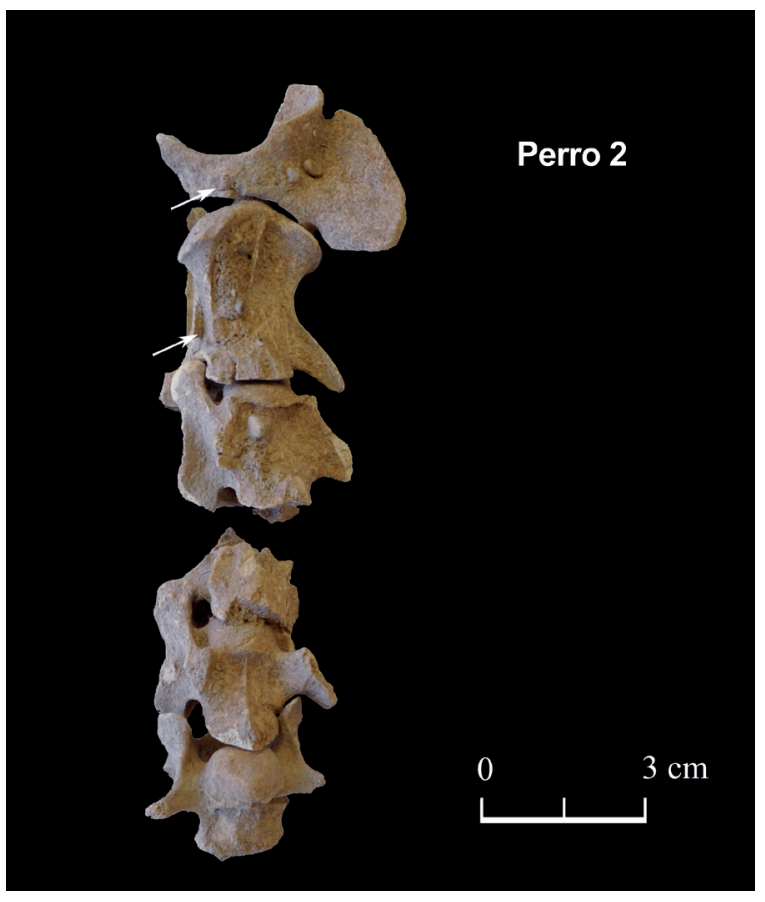

Fig. 11. Secuencia incompleta de las vértebras cervicales del perro $n .{ }^{\circ} 2$ en norma ventral con numerosas huellas: incisiones y muescas. mación de las vértebras responda a un proceso de esa índole, que normalmente también afectaría al resto del esqueleto del can. Por tanto, parece más probable que esta deformación se deba a una patología por estrés causada por una sobrecarga en la zona lumbar, es decir, que el perro debió de haber sido empleado como animal de carga o acémila.

Lamentablemente, los tramos de vértebras torácico-lumbares de este perro n. ${ }^{\circ} 2$ están incompletos y descuartizados $-\mathrm{y}$ ausentes en el n. ${ }^{\circ} 1-$, por lo que no es fácil ahondar en el diagnóstico. Pero hay otro indicio relevante: ninguno de los dos perros presenta evidencias de otras patologías postcraneales, por lo que podría sospecharse un tipo de carga que presiona sobre el lomo del animal, y -aunque con mucha cautela, dado el tipo de evidencia disponible- quedaría descartado el empleo del perro tirando de una narria o trineo, donde las patologías por estrés se asocian precisamente a la cintura escapular y pélvica, entre otras (Albizuri et al., 2011: 146-150). El empleo de perros como animales de transporte es bien conocido desde la Edad Media hasta el s. xx, épocas en las que uno o varios perros, tirando de pequeños carros, han sido usados para el transporte de personas, de mercancías, cargas de 


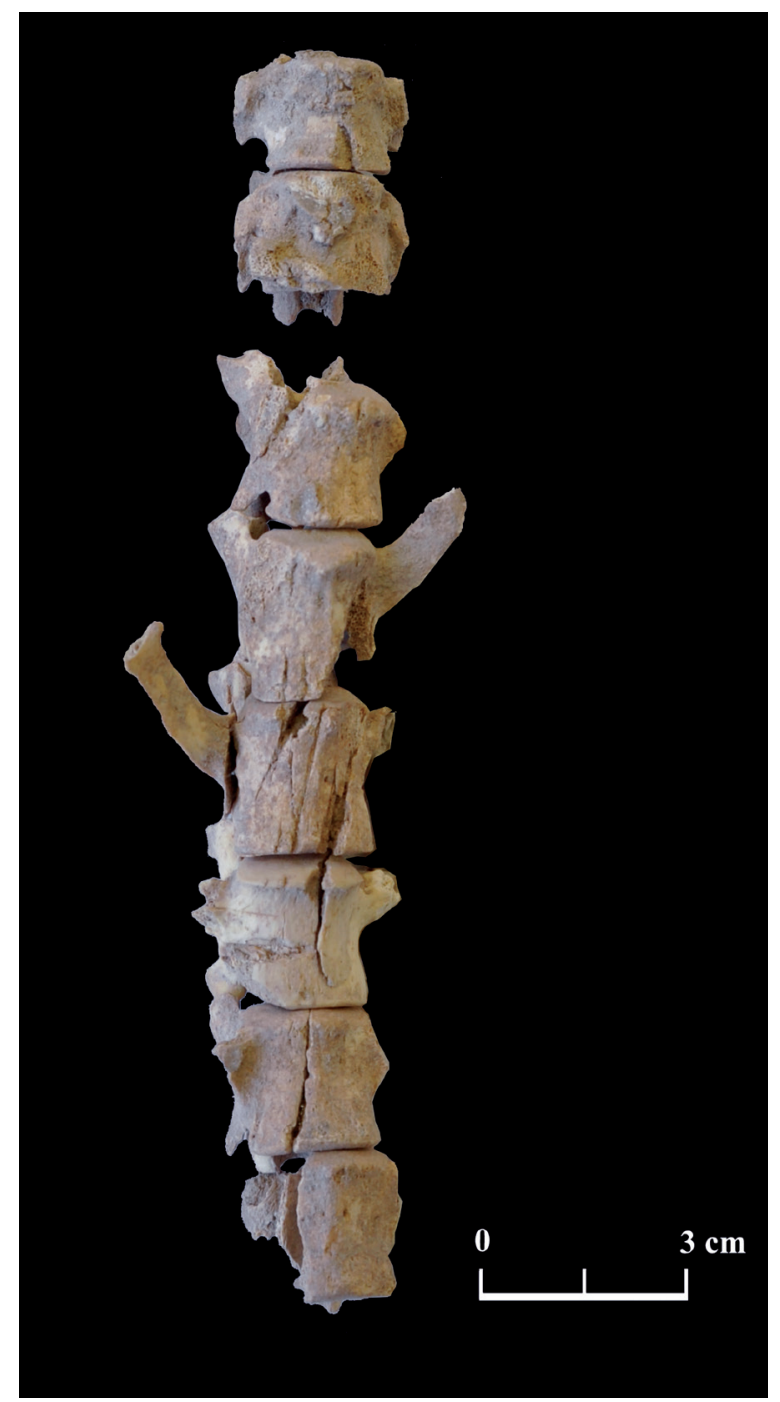

Fig. 12. Secuencia incompleta de las vértebras lumbares del perro n. 2 en norma ventral con numerosas huellas: muescas sagitales y transversas, troceados y fracturas lineales por acciones de percusión.

mineral (Albizuri et al., 2011: 141-142) o en el transporte militar (Gautier, 1990: 244). Pero últimamente se ha ampliado este papel canino al reconocerse la carga sobre el lomo, documentándose varios perros-acémila en el yacimiento del Bronce inicial de Can Roqueta II (Albizuri, 2011) ${ }^{17}$, a los que ahora se uniría, no sin problemas, el del yacimiento de La Huelga.

${ }^{17}$ Cf. también op. cit. n. 2.

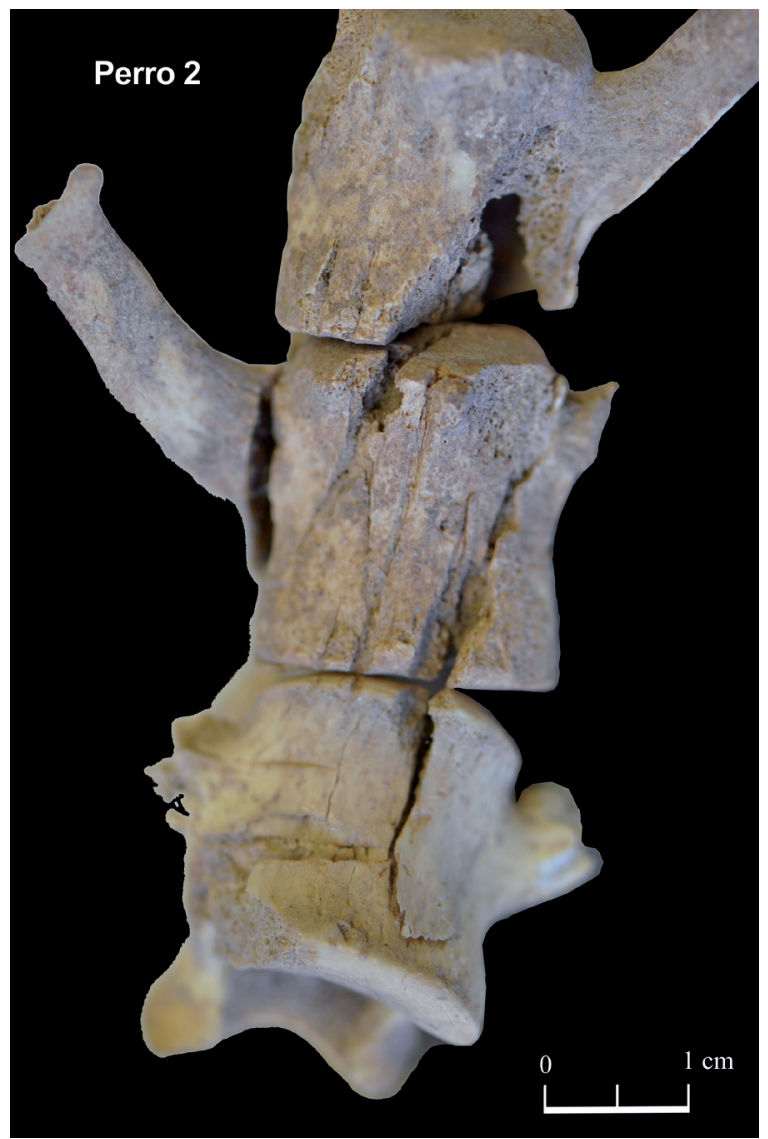

Fig. 13. Detalle de algunas de las vértebras lumbares del perro.$^{\circ} 2$, en norma ventral.

\subsection{Los restos de vacuno}

Por encima de parte del cuerpo del perro n. ${ }^{\circ} 1$ y hacia el borde oriental del hoyo y del conjunto de fauna se han localizado otras interesantes piezas que corresponden a vacuno (Bos taurus L.). Se trata de una base de clavija ósea derecha a falta de la extremidad distal, y de la mitad distal de un húmero derecho, algo alterada distalmente por las labores de excavación o por causas posdeposicionales. No resulta fiable asignar ambas piezas al mismo individuo, ni ha sido posible obtener algún dato osteométrico. Tan solo cabe señalar que la epífisis del húmero está distalmente fusionada, evidenciando una edad de juvenil-adulto. La diáfisis presenta proximalmente una fractura irregular que no permite extraer una conclusión fiable en torno al estado del hueso cuando fue fracturado (Fig. 15). 


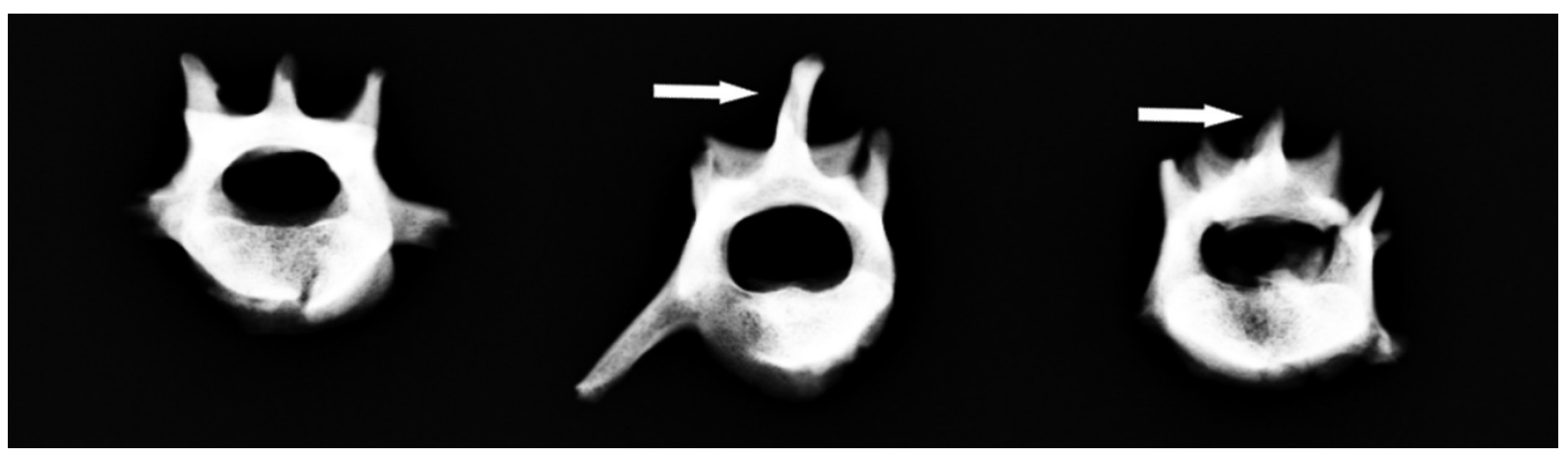

FIG. 14. Radiografías en norma cráneo-caudal de las tres vértebras lumbares mejor conservadas del perro n. ${ }^{\circ} 2$.

\section{Discusión}

\subsection{El depósito mortuorio ${ }^{18}$ del hoyo $36-C$}

Teniendo en cuenta las limitaciones anteriormente expuestas en relación con la asignación de las distintas porciones óseas a cada uno de los canes, el hallazgo de al menos dos perros en la base de un hoyo, su peculiar representación esquelética, así como las huellas de despiece merecen ser discutidas con mayor detalle, en orden a asegurar la intencionalidad del conjunto. Esta no ofrece duda alguna, al representar una selección deliberada de unas porciones anatómicas concretas: media carcasa de un perro en articulación y otro a falta de cráneo, pero con sus cuartos delanteros y su columna vertebral desarticulada o descuartizada.

Por el contacto directo de los huesos de ambos individuos y los restos de vacuno, parece que la secuencia deposicional se produjo en un lapso temporal breve, y las diferentes porciones en articulación también parecen indicar un proceso de esqueletización en espacio colmatado, es decir, cubierto por sedimento, una vez finalizada la colocación o vertido de las diferentes porciones de los tres animales.

Ante estos resultados cabe preguntarse qué pudo ocurrir con el resto de los esqueletos, cuando además las porciones con un mayor contenido de

${ }^{18}$ En el proyecto de investigación en el que se inscribe este trabajo se distingue entre los calificativos 'mortuorio' (relativo a la muerte) y 'funerario' (relativo al entierro y las honras fúnebres); el primero se emplea teniendo en cuenta la evidencia de manifestaciones en torno a la muerte -de seres humanos o de animales, e incluso de cosas- bien diferentes de los enterramientos.

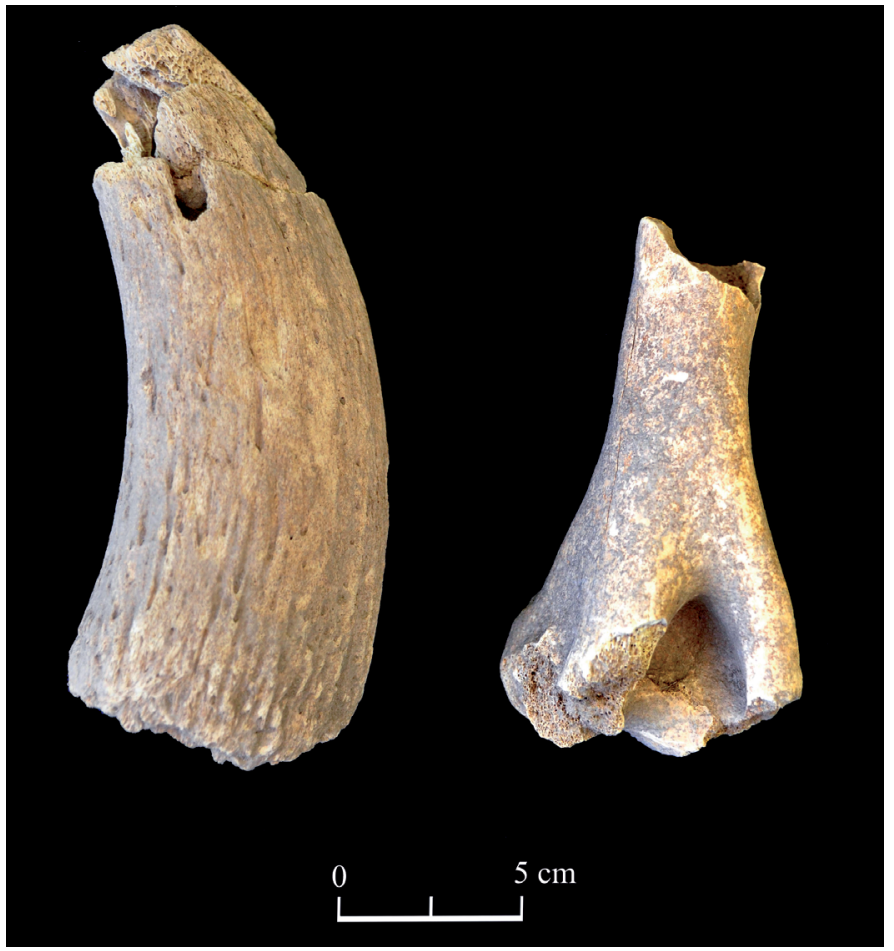

Fig. 15. Piezas de bovino (Bos taurus L.) que forman parte del depósito: fragmento de clavija ósea y mitad distal de húmero derecho, en norma caudal.

carne, es decir, las patas traseras, faltan por completo en ambos animales. Mientras que para el perro n. ${ }^{\circ} 1$ no se han obtenido evidencias macroscópicas de desarticulado en ninguna de las vértebras cervicales o en sus cuartos delanteros, no cabe duda en cuanto a la manipulación de la carcasa del otro can, pues las huellas de un exhaustivo descuartizado se manifiestan rotundamente desde una incisión en su atlas con la intención de su decapitado a numerosas 
muescas y troceados a lo largo de toda la columna vertebral (Figs. 9 y 11). Estas huellas muestran contundentes acciones de percusión que han provocado seccionados y fracturas en el resto de la columna. Además, el tipo de huellas parece indicar el empleo de un instrumento de filo metálico y cortante (Figs. 12 y 13). De igual modo, la localización de las mismas en la cara ventral de la columna hace patente un tipo de despiece que implica una serie de acciones previas y habituales en los trabajos de carnicería: desollado, eviscerado, descuartizado en grandes porciones, etc. El descuartizado en cuartos delanteros parece obvio para el can $n .^{\circ} 2$, como se observa en la Fig. 9, como también en su columna vertebral que aparece repartida en diferentes grupos de vértebras en conexión en torno al cráneo del otro can. Sin embargo, ese despiece, con la intención de abrir en canal el cuerpo del animal, ha sido realizado de forma bastante torpe, como lo demuestran las múltiples intervenciones sobre la columna y las secciones laterales de varias vértebras y da la sensación de que el filo del útil resbaló en numerosas acciones sin poder concluir el objetivo inicial (Fig. 13). Todas estas apreciaciones parecen argumentos lo suficientemente sólidos para descartar una recuperación de animales fallecidos, parcialmente depredados o carroñeados y posteriormente enterrados.

A falta del registro faunístico de todo el yacimiento, quedan en el aire preguntas de cierto alcance, por ejemplo, si el depósito corresponde a un evento excepcional o si, por el contrario, el perro era una especie habitualmente consumida en La Huelga. En cambio, recapitulando las diversas observaciones, cabe considerar bien establecido el carácter especial del conjunto, un depósito estructurado y con fuertes connotaciones simbólicas que siguen una clara secuencia deposicional:

1) El primer conjunto sobre el nivel de gravas del fondo es el perro n. ${ }^{\circ} 1$, un animal joven todavía en fase de crecimiento, que parece estar en conexión anatómica, aunque en la fotografía de la excavación resulta arriesgado estimar cuantas vértebras en conexión hubo y que, tal vez, pudieran haber continuado hacia el perfil del hoyo, al igual que algunos de los huesos largos de la pata delantera izquierda. Mientras que la pata delantera derecha está en conexión, la izquierda está parcialmente desarticulada como se observa el desplazamiento del radio con respecto a la ulna (Fig. 6). Este leve desplazamiento podría indicar quizás una exposición previa del cadáver a la intemperie, como se ha observado ocasionalmente con los restos humanos (Gómez et al., 2011; Esparza et al., 2012), o una fase inicial de esqueletización cuando se incorporaron los restos del segundo perro en este hoyo. Independientemente de esta cuestión, los restos de medio perro fueron arrojados o colocados en una zona marginal del fondo de un hoyo, detalle sobre el que luego se insistirá.

2) En un momento posterior, posiblemente muy poco después, el primer can parece haber sido cubierto con los cuartos delanteros de otro perro adulto, de menor talla que el primero, esta vez decapitado y descuartizado, mientras que diferentes porciones de su columna vertebral rodean al primero. Por tanto, ambos perros, con sus distintos tratamientos, integran un gesto de ofrenda próximo en el tiempo (Fig. 16).

3) Finalmente, se habrían colocado sobre el antebrazo del primer perro dos piezas seleccionadas de vacuno de las que subsiste un húmero y una clavija ósea -quizás envuelta entonces por su estuche córneo-, restos que podrían haber constituido una donación a esos individuos caninos o a otras entidades vinculadas a este tipo de prácticas.

La cuidadosa superposición de los citados restos de animales excluye el que fuesen tirados; antes bien, fueron colocados, y además ocupando solo una porción muy reducida del espacio disponible en el fondo del hoyo (Fig. 2), acaso porque en el sector restante se depositaban otros restos perecederos (partes cárnicas sin hueso, vísceras, piel, ofrendas vegetales, etc.) o bien porque allí se situaba quien o quienes realizaban tan ordenados gestos. Sea como fuere, esta llamativa distribución del espacio interno, que para el mismo ámbito cultural se ha señalado ya en otros depósitos faunísticos (Liesau, 2012: 245-246), se documenta también en sepulturas humanas (Esparza et al., 2008: 159; Gómez Pérez et al., 2011: 118-121), ilustrando una vez más la cercanía de ciertos seres en las prácticas mortuorias de Cogotas I.

Si la ausencia de los cuartos traseros y de la pelvis de los canes podría indicar un eventual consumo humano o por sus propios congéneres, lo cierto es que la parte depositada, especialmente del perro n. ${ }^{\circ} 1$, parece corresponder a algún tipo 
de comportamiento pautado que empieza a vislumbrarse tímidamente en algunos contextos del Bronce medio: así, en una sepultura de esta misma fase, la de inhumación infantil doble de Perales del Río (Madrid), junto a los pies de los niños yacía también la mitad delantera del cuerpo de un perro (Blasco et al., 1991: 59; fig. 5 y lám. Id). También debe recordarse que en la sepultura del yacimiento navarro de Cortecampo II perteneciente a una facies de la Edad del Bronce sincrónica de Cogotas I, dada la presencia de un vaso con decoración de dientes de lobo con líneas de boquique, el enterramiento humano iba acompañado por dos perros completos y las mitades delanteras de otros dos (Ramos Aguirre 2009: 64; y com. pers., enero 2013). Como luego se verá, la partición del perro en un plano transverso, es decir, en dos mitades, delantera y trasera, es un elemento sacrificial recurrente en diversas culturas.

La ausencia del cráneo del segundo perro no puede interpretarse debidamente, a falta de la información completa sobre la fauna del yacimiento y sobre una eventual aparición de tal

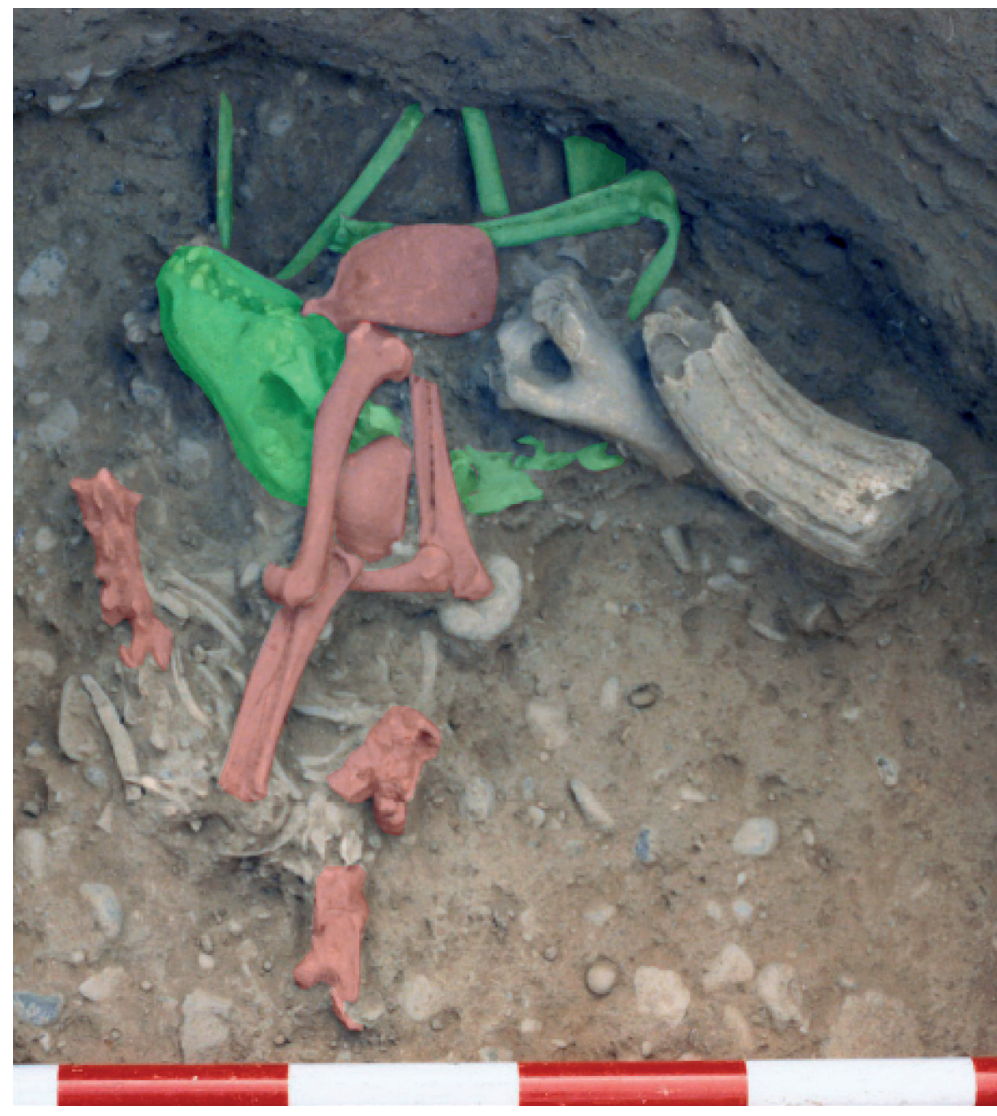

FIG. 16. Fotografía de detalle del conjunto faunístico; los huesos de cada perro identificados con seguridad se han coloreado para marcar el orden deposicional observado. cráneo colocado en algún otro hoyo o estructura del poblado. Debe al menos recordarse que la colocación de cráneos y mandíbulas de perros en hoyos y tramos de fosos es un hecho repetidamente observado en yacimientos peninsulares desde el Neolítico final y sobre todo durante el Calcolítico (Márquez, 2006; Valera et al., 2010; Liesau et al., 2008; Liesau, 2012). Pero sobre todo debe tenerse en cuenta que esa participación de los cráneos de canes en depósitos rituales continúa durante el Bronce antiguo (Albizuri, 2011) ${ }^{19}$ y en la propia fase Protocogotas I, como pone de manifiesto el hoyo F-319 de Camino de las Yeseras, un depósito con ofrendas cárnicas de vacuno, suido y un lechal, además del cráneo de un perro con sus primeras vértebras en conexión colocado boca abajo en el nivel de cierre

${ }_{19}$ Cf. también op. cit. n. 2. del hoyo (Liesau y Blasco, 2006: fig. 4) o el depósito de dos cráneos de perros asociados a unas fuentes carenadas en el poblado de Caserío de Perales (Blasco, 2012: 212).

Hace algunos ańos se propuso (Blasco, 1997: 84) para un depósito canino en la hoya $10 \mathrm{D}-2$ del poblado del Calcolítico y Bronce antiguo de La Loma del Lomo (Cogolludo, Guadalajara) que, dada su proximidad, podría haber estado en relación con la sepultura n. ${ }^{\circ} 9$ de este yacimiento. Por el contrario, en el caso de La Huelga debe descartarse una subordinación de ese tipo, pues no hay ningún enterramiento humano en los numerosos hoyos de toda el área excavada -solo se halló un fragmento craneal humano descontextualizado (Pérez Rodríguez et al., 1994: 23)-, lo que acentúa la singularidad del depósito canino, que no sería acompańante o "satélite", sino protagonista. 
Si el de La Huelga es indudablemente un depósito especial, no es sencillo establecer un diagnóstico definitivo acerca de su naturaleza: la interpretación como restos de banquete -reconocibles especialmente por su falta de conexión y por la selección de partes de mayor aprovechamiento cárnico (Albizuri, 2011: 10)- parece casi excluida ${ }^{20}$, mientras que su correspondencia a un rito sacrificial, aunque no segura, parece más compatible con los datos. Algunos trabajos sobre sacrificios de perros, como el de Wilkens (2006), establecen criterios arqueozoológicos -especialmente, esqueleto articulado, huellas de golpe o herida mortales, evidencia del objeto con el que se infligieron-, pero lo decisivo es el contexto arqueológico, su hallazgo "in association with clearly sacred spaces" (Wilkens, 2006: 135). En nuestro caso, la colocación, el tipo de selección anatómica y la manipulación parecen ir en este sentido, pero falta ese otro rasgo definitivo, ya que ni la zona del yacimiento ni la estructura donde se ubicó el depósito canino tienen algún rasgo distintivo conservado. Sobre este aspecto se volverá más adelante, matizando debidamente el carácter ritual que, por otra parte, se desprende de la propia repetición de conjuntos de restos faunísticos en el ámbito de Cogotas I.

\subsection{Referencias etnográficas e históricas para el registro arqueológico}

Que el perro desempeñe un importante papel en el terreno de lo simbólico no es ninguna sorpre$\mathrm{sa}$, siendo bien conocida la existencia de ofrendas caninas en banquetes y sobre todo su presencia en el ámbito funerario. En efecto, como consecuencia de los lazos afectivos que sus dueños han establecido con estos individuos y en los que incluso mimetizan gestos humanos (Serpell, 1995b: 2; Clutton-Brock, 1999: 50), no es infrecuente la comparecencia del perro como acompañante en sepulturas humanas, y hasta se conocen casos en que el can es el sujeto principal en verdaderos enterramientos de perros (Day, 1984; Larsson, 1994; Lupo y Janetski, 1994; Gräslund, 2004; Losey et al., 2011), algunos de ellos también en el ámbito

${ }^{20}$ No es posible excluirla por completo, dada la ausencia de los cuartos traseros de ambos perros, precisamente las partes de mayor aprovechamiento cárnico. peninsular (Verdú, 2004; García Blánquez et al., 2003; Lomba et al., 2009).

Una somera aproximación a la bibliografía etnográfica e histórica acerca de las prácticas culturales que incluyen restos de perro conduce no solo a las formas antes citadas, sino a otras extraordinariamente abundantes y variadas, entre las que destacan las múltiples clases de sacrificios, practicados en Grecia incluso en fechas muy recientes, que pueden resumirse siguiendo a Sergis (2010), quien distingue entre sacrificios catárticos, realizados dentro de ritos de purificación, y sacrificios de fertilidad, humana o de la tierra, los cultivos y los ganados. Algunas referencias provenientes del mundo antiguo son especialmente sugerentes: por ejemplo, en el mundo etrusco, un texto del s. II a. C. describe la Hondia, o ceremonia del can, sacrificado en honor de Hondo, una divinidad relacionada con la agricultura; en este caso, una parte del perro, concretamente los miembros traseros y las vísceras, se retira, como la carne, y se contempla en una fosa. Posteriormente se cocina y se practican libaciones, se ofrece a la divinidad en el altar, mientras que otras partes son consumidas por los oferentes. Después de las oraciones y los actos libatorios, el resto del can era enterrado al pie del altar (Wilkens, 2006: 132). Otras veces se citan también posibles sacrificios fundacionales o protectores a partir de la propia evidencia arqueológica de restos de perros y otros animales despiezados que se han hallado en diversas estructuras y pozos (De Grossi y Minniti, 2006: 65). Recuérdense, en este sentido, ciertos depósitos especiales de la Edad del Hierro, como el hallado en el hillfort inglés de Danebury, con una pata de caballo colocada sobre un perro completo, que fue interpretado como ofrenda propiciatoria a deidades ctónicas, protectoras de los contenedores subterráneos de grano (Cunliffe, 1974: 570-571), o el del yacimiento ibérico de Mas de Castellar de Pontós, cuyos sacrificios caninos han sido interpretados -siguiendo un pasaje de Ovidio (Fast. IV) sobre las Robigalia - en relación con la preservación de las mieses frente a la roya (Colominas, 2008; Adroher et al., 1993: 62-63). Pero la interpretación final es siempre arriesgada, y para estos casos podrían haberse aducido otras referencias del mundo clásico, por ejemplo, el augurium canarium, un sacrificio de perros que, como relata Plinio (Nat. Hist., XviII.3.14), se hacía para propiciar la maduración del grano. 
Por el modo de despiece realizado resultan especialmente interesantes los sacrificios caninos destinados a la purificación de ejércitos del mundo antiguo, narrados por Tito Livio o Quinto Curzio, o por las tabletas hititas: una vez descuartizado el perro por la mitad en sentido transversal, las mitades delantera y trasera eran lanzadas hacia un lado y otro, y el ejército pasaba entre medias, quedando así purificado (Masson, 1950; De Grossi, 2008: 73). Y en investigaciones etnológicas recientes se ha observado -por ejemplo, entre los Turkana de Kenia- que el corte transversal, a nivel del diafragma, de los perros se prescribe específicamente en el caso de los sacrificios relacionados con graves amenazas (Liénard, 2006: 346).

En cuanto a la asociación entre perro y restos de vacuno, es menos frecuente en los textos, pero arqueológicamente se conocen en el Neolítico de los Balcanes sacrificios de can, que una vez desmembrado y acompañado por un cuerno de vacuno, así como huesos de ciervo y un hacha lítica, se depositaban en la zanja fundacional de las cabañas (Cultraro, 2005: 488). En la Península Ibérica este tipo de asociación se ha observado en el yacimiento de Marroquíes Bajos (Jaén), donde en la base de una fosa de sección piriforme se documentó el esqueleto de un perro completo, mandíbulas de otros cánidos y restos deteriorados de otros bovinos, cuernos y vértebras fundamentalmente y que los autores han interpretado como un enterramiento ritual (Burgos et al., 2001: 407). Otro caso no menos complejo es el de Camino de las Yeseras (Madrid), donde en una cubeta en la base de un hoyo se alojaron restos de varias especies, así como un cráneo de perro entre tierras cenicientas, todo ello cubierto por el cráneo de un gran bovino, cuyas clavijas óseas fueron embadurnadas con ocre rojo (Liesau et al, 2008: 107). Esperemos que futuros hallazgos y más estudios arqueozoológicos permitan caracterizar mejor esta interesante asociación de bovinos con canes en sociedades cuya base pecuaria descansa especialmente en la cría del ganado vacuno.

\subsection{En torno al posible significado del depósito de La Huelga}

Tratando de concretar alguna de las posibilidades que ofrecen las referencias examinadas, habría que recordar que para el grupo arqueológico Cogotas I ya se propuso (Blasco, 1997: 84) que los animales colocados en depósitos especiales podrían ser el trasunto de las personas -el depósito sería una especie de cenotafio ${ }^{21}$, en el que la ausencia del difunto es suplida por el animal-, pero en La Huelga ni siquiera hay evidencias funerarias que lo avalen, sino todo lo contrario, especialmente si se parte de la hipótesis de que el rito funerario normativo de Cogotas I era la exposición de cadáveres, y la sepultura en hoyo una excepción reservada para determinadas circunstancias (Esparza et al., 2012).

Si pasamos a la hipótesis de un sacrificio, ¿qué sentido podría tener en La Huelga? Ciertamente, podría proponerse su correspondencia con eventuales ritos de fundación ${ }^{22}$ o de clausura de cabañas ${ }^{23}$, etc., pero sin ningún indicio mínimamente firme, al no presentar este hoyo donaciones de recipientes cerámicos, artefactos o las dimensiones ni la estratigrafía propia de lugares de hábitat como son las de las cabañas. Y tampoco hay nada que permita argumentar que el perro haya desempeñado el papel de víctima sustituta en un marco de sacrificios humanos. Dejando ahora la eventual relación entre el sacrificio y la presumible condición de perro de

21 La interpretación del cenotafio fue propuesta por Larsson (1994: 568) para un enterramiento canino del Mesolítico nórdico, pero en este caso basándose en un hecho significativo: el perro fue enterrado con un ajuar característico de las tumbas humanas.

22 Palomino et al. (1999: 36) sugieren que la ofrenda de vacuno del hoyo 17 de El Cerro (La Horra, Burgos) pudiera haber sido un sacrificio propiciatorio en relación con la fundación del sitio. Pero el caso más claro podría ser el del Caserío de Perales (Getafe), con dos hoyos geminados, uno de ellos con porciones conexas de bovino y el otro con vasos cerámicos completos y colocados boca abajo (Blasco et al., 1984-85).

23 Recientemente apuntábamos (Esparza, 2009: 187; Sánchez Polo, 2010: 180) la posibilidad de que el hoyo 56-57 de la Fábrica de Ladrillos (Getafe, Madrid) hubiese servido para enterrar ritualmente una cabaña, incluyendo entre sus restos una piel de perro. Desde luego, se carece de una evidencia inequívoca como la que avala la etnoarqueología, por ejemplo, los canes completos hallados en el último suelo de habitación de las cabañas de Keatley Creek (British Columbia, Canadá), que se han interpretado como depósitos de clausura relacionables con la muerte del dueño (Crellin, D. F.: Is there a dog in the house?: The cultural significance of prehistoric domesticated dogs in the Mid Fraser River Region of British Columbia. Unplublished MA thesis. Presented in 1994, Simon Fraser University, p. 267). 
carga de uno de los dos canes sacrificados en La Huelga, apenas quedaría, como mera posibilidad, aquella del sacrificio propiciatorio a determinadas entidades protectoras de los espacios domésticos, basada en la presunta condición de silos atribuida de forma inconcreta a todas las subestructuras, pero no probada para el hoyo 36-c. En cambio, si se recuerda el proceso de exposición conjeturado en el caso del perro n. ${ }^{\circ} 1$ de La Huelga, no se debería descartar algún otro supuesto, desconocido hasta ahora en nuestro ámbito: así, en América del Norte el descuartizamiento de perros y su inclusión en hoyos ha sido relacionado con ceremonias y festivales de agregación invernal realizadas por 'sociedades secretas' masculinas ${ }^{24}$, habiéndose documentado en la etnografía de la zona que los perros o partes de los perros sacrificados con tal motivo eran temporalmente colgados en postes en el exterior de la vivienda donde la ceremonia tenía lugar. Una vez concluidas estas ceremonias, dichas porciones eran enterradas en hoyos, ya que por su condición simbólica recibían un tratamiento diferente al de los simples desechos. Similares gestos -sacrificio de los perros, exposición en postes y entierro de sus restos en hoyos- se producían también con ocasión de la muerte de determinados individuos en esa misma región ${ }^{25}$.

La escasa información disponible no permite, pues, ir demasiado lejos en este delicado terreno ya que, a falta de más datos contextuales e incluso del diagnóstico sobre la forma de muerte, es prácticamente imposible adentrarse en los detalles concretos, y no digamos en las motivaciones; y como ya se ha apuntado en otras ocasiones, los trabajos de campo y los estudios posteriores tienen que ofrecer sólidos argumentos para poder interpretar una intencionalidad simbólica en estos conjuntos (Morris, 2008, 2011). Es verdad que en aquellos casos de canes enterrados, ya sea como acompañantes de humanos o en verdaderas tumbas de perro, cabe hacer razonables especulaciones: su privilegiado tratamiento podría ser un gesto emotivo en correspondencia a un especial apego a sus dueños, un papel relevante para una familia, etc. (Valiente, 1992: 237); a su condición de cazador experto, compañero leal, diligente guardián, animal de compañía, consumido

${ }^{24}$ Crellin: op. cit. n. 23, pp. 270-272.

${ }^{25}$ Ibidem, p. 271. en acontecimientos excepcionales (Benecke, 1994; Serpell, 1995c: 249; Serpell y Jagoe, 1995; Lapham, 2010: 454); a su papel como pastores o acémilas (Albizuri et al., 2011) 26 $^{26}$ o perros boyeros, como se ha sugerido (Vega et al., 1998: 131) con discutibles argumentos. Por el contrario, en el caso de los canes sacrificados, como pudiera ser el del yacimiento palentino, es más difícil concretar los motivos para la selección de las víctimas, ya que las posibilidades podrían ser, además de las mencionadas, otras bien diferentes -estar afectado de rabia (Sergis, 2010: 77), por ejemplo; por su mala conducta, o por su raro aspecto en cuanto a pelaje o distinto color en ambos ojos, etc.-, eventualidades que, aun estando documentadas en la etnografía o en el mundo clásico $^{27}$ no pueden probarse arqueológicamente. En el caso de La Huelga, la complejidad del conjunto no parece encajar con una mera actitud de repulsa, que podría servir a lo sumo para otros depósitos individuales en hoyos.

Por el contrario, la probable condición de perroacémila del $n .^{\circ} 2$ del yacimiento palentino podría ser la clave de la interpretación: así, haciéndose eco de la proximidad de algunos perros de carga a sepulturas humanas, Albizuri et al. (2011: 151) han sugerido que en Can Roqueta II (Barcelona), como en otras sociedades prehistóricas, se habría dado una selección de los perros más importantes con fines sacrificiales relacionados con la muerte humana. En La Huelga no se ha observado esa relación, por lo que no puede llegar a concretarse tanto la finalidad de la conducta, pero sí parece coincidir con el yacimiento catalán en que los perros-acémila habrían sido previamente eviscerados y descuartizados (ibid.: 144-145), lo que parece indicar la existencia de una pauta. Esta, como otras ya mencionadas - troceado o sección transversal de los perros, selección de la mitad-, vendrían a corroborar la hipótesis del sacrificio.

26 Cf. también op. cit. n. 2.

27 El perro que se sacrificaba en las Robigalia era de color rojizo, según Ovidio (Fast., IV). También en los sacrificios de los Turkana de Kenia, el color de la víctima tiene tanta importancia como el procedimiento con el que se le da muerte (Liénard, 2006: 346 y 359). En ciertos casos, el acento del sacrificio de perros recae también sobre circunstancias todavía menos accesibles a la arqueología, como el hecho de ser realizados por una mujer, en silencio y con la mano izquierda (Benkheira, 1999: 94, n. 17). 


\subsection{Encuadre del depósito}

Más allá del controvertido significado de este depósito, parece razonable aprovechar el hallazgo de La Huelga en otro sentido bien diferente. En efecto, puede ser orientado hacia una investigación comparativa de larga trayectoria sobre las variaciones en la relación entre humanos y perros en la Prehistoria: podría sospecharse que el papel simbólico de estos animales -y, en general, la percepción humana de los animales- estaban relacionados con procesos sociales y culturales más complejos. Por ello, deberían investigarse en nuestro ámbito los cambios en las formas de deposición de los restos de perros, como se ha hecho en otros, por ejemplo, en el mundo griego, donde se ha observado que, tras haberse comido perro en el Bronce antiguo, los canes pasan a desempeñar a partir de la etapa micénica papeles de gran importancia en los ámbitos funerario y religioso (Day, 1984).

Ciertamente, en la Edad del Bronce meseteña ya se han tanteado también algunas tendencias, aun contando todavía con un reducido número de hallazgos. Así, C. Blasco (1994: 156-159) apuntaba que, al igual que sucede con los enterramientos humanos, que se enrarecen paulatinamente desde el Bronce antiguo, también lo hacen los depósitos de animales completos y articulados, seńalando posiblemente esta tendencia un cambio en las pautas rituales. En trabajos posteriores, una mayor información ha permitido alguna precisión, de forma que entre el Bronce antiguo y el Protocogotas I se habría producido bastante continuidad en la aparición de variados depósitos -a veces de partes poco aprovechables, otras de porciones de gran rendimiento cárnico, algunos de animales completos que recuerdan los enterramientos humanos (Blasco, 2004: 569 y 572)-, siendo en cambio muy marcado el contraste con la fase de Cogotas i Pleno, en la que se producirá la práctica desaparición de este tipo de manifestaciones centradas sobre restos faunísticos. Además, no carece de interés el que también se adviertan otras señales de cambio coincidentes en el tiempo con la que se ha mencionado, como el abrupto declive en cuanto a sepulturas humanas o la desaparición de los depósitos integrados por molinos barquiformes -que ceden el paso a los depósitos de recipientes cerámicos completos-, por no citar el barroquismo en la decoración cerámica e incluso el aumento en la capacidad de las fosas de almacenamiento de los hoyos (Liesau y Blasco, 2006; Blanco, 2011; Blasco, 2012; Sánchez Polo, 2012).

Lo que se entrevé, en definitiva, es que las diferencias en la 'cultura material' que han permitido el deslinde entre Protocogotas y Cogotas I "han de vincularse con cambios eminentemente simbólicos, plasmados en sus prácticas ritualizadas" (Blanco González, 2011: 141). Ahora bien, para profundizar en ese tipo de propuestas interpretativas se necesitan una excavación y análisis muy detallados, y en el caso de los depósitos faunísticos deberá observarse lo sucedido con cada una de las especies representadas, individualizando la secuencia desde una perspectiva tafonómica, las porciones, los caracteres osteomorfológicos, las huellas antrópicas, etc., sobre todo en cuanto al perro, dada su particular relación con los seres humanos, que en muchas culturas ha hecho que fuese considerado como el primero entre los animales, e incluso como un ser más próximo a lo humano que a los otros animales (Serpell, 1995b).

En esa línea, y a título de ensayo, se recogen en la Fig. 17 las variaciones que el tratamiento mortuorio del perro parece haber sufrido en la Meseta desde el Calcolítico a Cogotas I, utilizando cuatro categorías que parecen tener suficiente entidad: a) sepulturas humanas en las que el perro aparece como acompañante; b) enterramientos de perro; c) cráneos de perro; y d) porciones seleccionadas de perro, asociadas a otras especies. Lamentablemente no puede incluirse en la comparación el consumo de carne de perro, ya que si bien esta conducta pudo tener en esta región, como en otras de Europa y de la propia Península Ibérica, una amplia extensión y continuidad (vid. por ejemplo, Sanchís y Sarrión, 2004: 180), lo cierto es que hasta ahora hay una gran escasez de citas bibliográficas de cinofagia en la Meseta. No sabemos si esto es un simple efecto de la falta de investigación especializada o si podría realmente responder a un comportamiento cultural; en este último caso, sería lo contrario del que se observa por ejemplo en el ámbito argárico, donde un consumo más o menos ocasional de carne de perro (Manhart et al., 2000: 225-236) encaja con su 


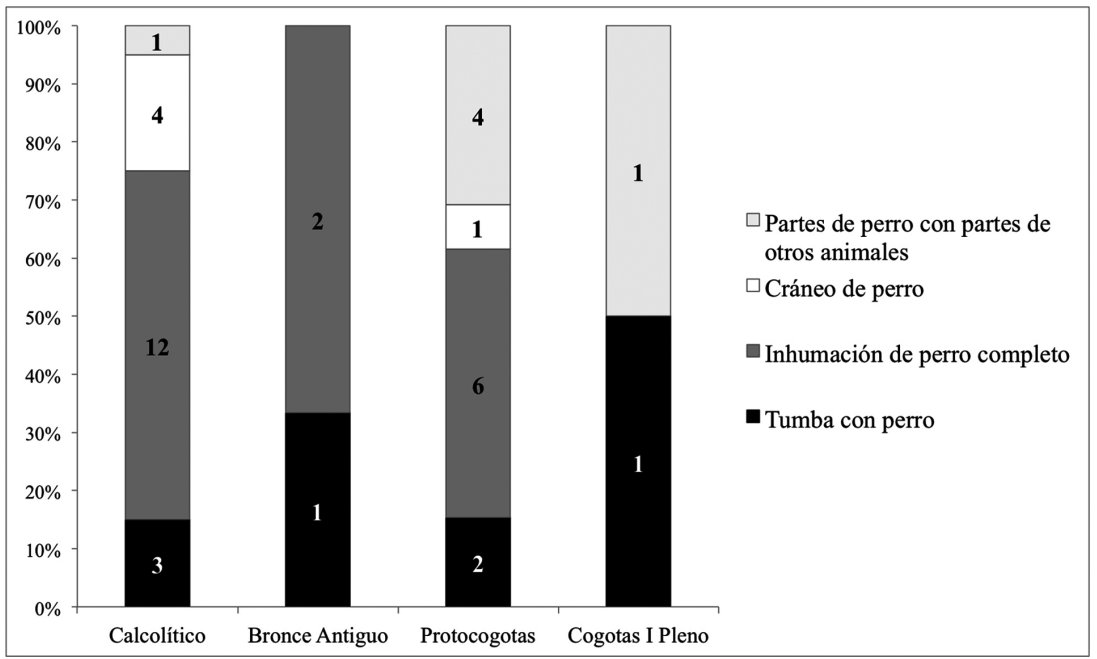

Fig. 17. Variaciones en los depósitos con perro desde el Calcolítico al Bronce tardio; en el interior de las barras se constata el número de depósitos. completos y también cráneos de canes de forma aislada. Como nota distintiva, en la fase Protocogotas I adquieren ciertamente mayor relieve los depósitos que reúnen ciertas partes de perros con restos de otros animales, es decir, los conjuntos que, como el de La Huelga, parecen resultar de complejas prácticas de partición o fragmentación, esto es, la fractura o despiece intencionado y la selección de ciertos restos parciales -animales, humanos o de cultura material-, en relación con procesos liminales o con la construcción de identidades (Blanco, 2011: 132), prácticas que tendrán todavía continuidad en el Cogotas i pleno. irrelevante papel en el mundo simbólico, a juzgar por su ausencia en sepulturas y depósitos de fauna articulada.

Los datos que se recogen en la Fig. 17, rastreados en la bibliografía ${ }^{28}$ parecen mostrar - obviando ahora la diferente calidad y precisión cronológica de muchos de ellos, y aun de las propias fases cronológicas- una continuada tendencia a la disminución numérica de las diversas modalidades de depósitos en los que comparece el perro: como sucedía con otras manifestaciones, también aquí el cambio más profundo parece coincidir con la plenitud de Cogotas I. En segundo lugar, el Protocogotas I manifestaría bastante coincidencia con respecto al Calcolítico -Precampaniforme y Campaniforme-: en efecto, tras el episodio del Bronce antiguo, menos rico al menos hasta ahora en este tipo de depósitos caninos, volvieron a enterrarse con regularidad perros con humanos -siempre infantiles-, perros más o menos

${ }^{28}$ Los datos que soportan esta gráfica de la Fig. 17 proceden de Liesau (2012), con el ańadido de algunos hallazgos poco conocidos, como los de Pinto (López Covacho et al., 1996) e Illescas (García Lerga et al., 2008) y sobre todo los de los depósitos calcolíticos de canes del centro de la cuenca del Duero estudiados por A. García Barrios (com. pers. a A. Sánchez Polo) en su tesis doctoral Los inicios de la Edad del Cobre en el valle medio del Duero. Una aproximación a los modos de vida en el centro de la Meseta Norte, presentadada en 2008 en la Univ. de Valladolid.

\section{Conclusiones}

1) Como se ha visto, la participación del perro en la esfera simbólica es extraordinariamente variada, pudiendo recordarse, como simple botón de muestra, que en el mundo hitita, griego y romano una gran heterogeneidad caracteriza tanto las numerosas fórmulas sacrificiales, como las del mundo de los muertos o de los banquetes rituales, pero además el perro también acompaña a deidades protectoras del parto, se le atribuyen virtudes sanadoras, etc. (De Grossi y Minniti, 2006; Trantalidou, 2006; Albizuri, 2011) ${ }^{29}$. Se hacen patentes así los límites de cualquier investigación que cuente solamente con fuentes arqueológicas. Así, de la misma forma que es exigible con las sepulturas humanas, también los depósitos caninos, y en general los de fauna, deberían contar, como venimos reclamando, con un registro minucioso, especialmente en cuanto a planimetría y fotografía de campo y al conjunto de los elementos del relleno, que facilite el estudio arqueozoológico, la datación, la adscripción cronocultural, etc. Como contribución a esa tarea básica va el presente artículo, con el

${ }^{29}$ Cf. también op. cit. n. 2. 
cual -partiendo de un material arqueológico que afortunadamente y a diferencia de lo que sucede en no pocas ocasiones fue recuperado por los excavadores y adecuadamente conservado en el Museo- se ha intentado exponer los límites del registro, al tiempo que plantear las posibilidades interpretativas y el significado social de estos depósitos a la luz de fuentes literarias y etnográficas.

2) En el caso del depósito de La Huelga, el registro del que se dispone, si bien no excluye por completo alguna de las posibilidades, como la del banquete, es compatible con otras -sacrificio propiciatorio, adivinatorio, de purificación o de prevención- que no pueden concretarse más, aunque el carácter de acémila del perro n. 2 podría ser, como se dijo, un elemento clave. En todo caso, el hoyo 36-c donde el depósito se aloja no tiene ninguna característica especial -carece de rasgos distintivos frente a los demás hoyos y no está en un espacio singular-, por lo cual, antes que considerarlo como perteneciente a una esfera específicamente sagrada, separada de las actividades cotidianas, debe de corresponder más bien a la compleja racionalidad esbozada en su día por J. Brück (1999) al analizar la indisolubilidad entre lo 'ritual' y lo 'secular' en sociedades prehistóricas, al contrario de lo que ocurre en la actualidad, aspecto en el que también ha puesto énfasis Bradley (2003) con la denominada ritualización de la vida doméstica.

3) La reiteración de observaciones documentadas en otros yacimientos hace posible proponer, adoptando una perspectiva más amplia, que el depósito de La Huelga corresponde a una práctica social e inmersa en el ámbito de lo cotidiano, en la que se procedió a destruir o quizás repartir unos bienes susceptibles de diversos aprovechamientos. El sentido último de esta destrucción de recursos podría haber sido una exhibición de poder o -teniendo en cuenta que en el ámbito de estudio por el momento no hay datos seguros acerca de jerarquización social- tal vez un gesto de carácter simbólico, eventual pero pautado, que responde a una práctica de larga duración.
4) En este depósito, que en cierta medida recuerda las sepulturas humanas en hoyo, cabría ver un carácter liminal, intermedio entre vida y muerte, como lo es también la propia posición del perro entre los humanos y los no humanos: es un animal, pero actúa como auxiliar en la caza y en la carga, y como guardián de la casa y del ganado, especialmente el vacuno, base de la economía ganadera de las gentes del Bronce medio en la Meseta. ¿Será esa liminalidad lo que se representa en la asociación de restos caninos y de vacuno?

5) Vinculados probablemente a un mundo sobrenatural, formando parte de ágapes funerarios o de ceremonias de otra índole -fundacional, de clausura, de agregación, etc.-, los depósitos con restos de canes, ya sean desarticulados, completos o como este de La Huelga, constituyen, como decía Larsson (1991: 38), "fonemas de un lenguaje simbólico", de modo que si se aspira a entender ese lenguaje debe comenzarse por caracterizarlos con el mayor rigor. Teniendo en cuenta que la mayoría de los yacimientos de campos de hoyos no se conocen en extensión, es imprescindible estudiar y relacionar las diferentes estructuras que contengan cualquier resto de esta especie con el objetivo de caracterizar los hallazgos y acumular evidencias de unos comportamientos simbólicos pautados, que perviven durante Cogotas I como la costumbre ancestral del trasiego de sus cráneos. Pero el conjunto de La Huelga se muestra mucho más complejo conceptualmente, con animales sometidos a un exhaustivo descuartizamiento, una cuidadosa selección de sus porciones y tal vez también acompañados por otras ofrendas de origen orgánico -pieles, vísceras, sangre, etc.-, si se recuerda la parafernalia en los protocolos de sacrificios animales en el mundo antiguo. Por tanto, no se trata de meros despojos arrojados como basura, sino que se encuadran en unas prácticas donde el mundo de Cogotas I no es en absoluto ajeno a aspectos ideológicos novedosos y en las que parece que nada se dejó al azar. 


\section{Bibliografía}

Adroher, A. M.; Pons i Brun, E. y Ruiz de Arbulo, J. (I993): "El yacimiento de Mas Castellar de Pontós y el comercio del cereal ibérico en la zona de Emporion y Rhode (siglos IV-II AC)", Archivo Español de Arqueología, 66, pp. 31-70.

Albizuri, S. (2011): “Animales sacrificados para el cortejo fúnebre durante el Bronce Inicial (2300-1300 cal BC). El asentamiento de Can Roqueta II (Sabadell, Barcelona)", Quaderns de Prehistòria i Arqueología de Castelló, 29, pp. 7-26.

Albizuri, S.; Fernández, M. y Tomás, X. (2011): "Evidencias sobre el uso del perro en la carga durante el Bronce Inicial en la Península Ibérica: el caso de Can Roqueta II (Sabadell, Barcelona)", Archaeofauna, 20, pp. 139-155.

Bellido, A. (1996): Los campos de hoyos. Inicios de la Economía agrícola en la Submeseta Norte. Studia Archaeologica, 85. Valladolid: Univ. Valladolid.

Benecke, N. (1994): Der Mensch und seine Haustiere. Stuttgart: Theiss.

Benkheira, M. H. (1999): "Lier et séparer. Les fonctions rituelles de la viande dans le monde islamisé", L'Homme, 39 (152), pp. 89-114. http://dx.doi.org/10.3406/hom.1999.453664

Blanco, A. (2011): "Práctica social, memoria y ritual en Cogotas I. Esbozo teórico para un enfoque renovado”, Trabajos de Prehistoria, 68 (1), pp. 123-146. http://dx.doi.org/10.3989/tp.2011.11062

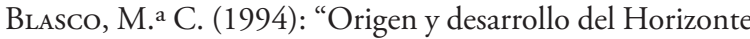
Cogotas I en el Alto Tajo”. En $1^{\circ}$ Congresso de Arqueologia Peninsular, Actas IV. Trabalhos de Antropologia e Etnografia, 34 (3-4). Porto, pp. 151-166.

Blasco, M. ${ }^{a}$ C. (1997): "La Edad del Bronce en el interior peninsular. Una aproximación al II Milenio AC en las cuencas de los Ríos Duero y Tajo", Cuadernos de Prehistoria y Arqueología de la Universidad Autónoma de Madrid, 24, pp. 59-100.

Blasco, M. ${ }^{a}$ C. (2004): "Hacia una definición del Horizonte Cogotas I: algo más que un estilo cerámico”. En Hernández, L. y Hernández, M. S. (eds.): La Edad del Bronce en tierras valencianas y zonas limitrofes. Alicante-Villena: Inst. ${ }^{\circ}$ Juan Gil-Albert-Ayto. Villena, pp. 564-584.

Blasco, C.; Blanco, J. F.; Liesau, C.; Carrión, E.; GarCía, J.; Baena, J.; Quero, S. y Rodríguez de la Esperanza, M. ${ }^{\mathrm{a}}$ J. (2007): El Bronce Medio y Final en la Región de Madrid. El poblado de la Fábrica de Ladrillos de Getafe. Estudios de Prehistoria y Arqueología Madrileñas, 14-15. Madrid: Museo de los Orígenes.

Blasco, C.; Calle, J. y Sánchez-Capilla, M. a L. (1995): "Fecha de $\mathrm{C}^{14}$ de la fase Protocogotas I del yacimiento del Caserío de Perales del Río", Cuadernos de Prehistoria y Arqueología de la Universidad Autónoma de Madrid, 22, pp. 83-100.

Blasco, M. ${ }^{a}$ C.; Sánchez Capilla, M. ${ }^{a}$ L.; Calle, J.; RoBles, F. J.; González, V. M. y González, A. (1991): "Enterramientos del horizonte Protocogotas en el Valle del Manzanares", Cuadernos de Prehistoria y Arqueología de la Universidad Autónoma de Madrid, 18, pp. 55-112.

Blasco, M. a C.; Sánchez-Capilla, M. ${ }^{a}$ L.; Caprile, P. y Calle, J. (1984-85): "Depósito votivo en un yacimiento de la Edad del Bronce en el valle del Manzanares (Perales del Río, Getafe, Madrid)", Cuadernos de Prehistoria y Arqueología de la Universidad Autónoma de Madrid, 11-12, pp. 11-23.

Bradley, R. (2003): "A Life Less Ordinary: the Ritualization of the Domestic Sphere in Later Prehistoric Europe", Cambridge Archaeological Journal, 13, pp. 523. http://dx.doi.org/10.1017/S0959774303000015

BRÜCK, J. (1999): "Ritual and rationality: Some problems of interpretation in European Archaeology", Journal of European Archaeology, 2 (3), pp. 313-344. http://dx.doi.org/10.1177/146195719900200303 http://dx.doi.org/10.1179/eja.1999.2.3.313

Burgos, A.; Pérez, C. y Lizcano, R. (2001): "Actuación arqueológica realizada en la piscina comunitaria de los bloques AI, A2, A3, A6, A7, y A8 del sector UA-23 de Marroquíes Bajos de Jaén", Anuario Arqueológico de Andalucía, pp. 402-428.

Clutton-Brock, J. (1999): A Natural History of Domesticated Mammals. Cambridge: Cup.

Colominas, L. (2008): "Els animals en el conjunt de les pràctiques socials desenvolupades a l'establiment rural de Mas Castellar (Pontós, Girona)", Cypsela, 17, pp. 219-232.

Cultraro, M. (2005): "La tomba 6 di Fontenoce/area Guzzini di Recanati (Macerata) e il rituale del sacrificio del cane". En Atti della XXXVIII Riunione Scientifica Preistoria e Protostoria delle Marche (Portonovo, Abbadia di Fiastra, ottobre 2003). Firenze: Istituto Italiano di Preistoria e Protostoria, pp. 481-493.

Cunliffe, B. (1974; $4^{\text {th }}$ ed.): Iron Age Communities in Britain. London: Routledge. http://dx.doi.org/10.4324/9780203326053

DAY, L. P. (1984): "Dog Burials in the Greek World”, American Journal of Archaeology, 88, pp. 21-32. http://dx.doi.org/10.2307/504595

Daza Perea, A. (2011): "Los depósitos de perros en Camino de las Yeseras". En Blasco, C.; Liesau, C. y Ríos, P. (eds.): Yacimientos calcoliticos con Campaniforme de la Región de Madrid: Nuevos estudios. Madrid: UAM, pp. 211-222.

De Grossi, J. (2008): "L'uso dei cani nei riti di fondazione, purificazione e passaggio nel mondo antico". En D’Andria, F.; De Grossi, J. y Fiorentino, G. (eds.): 
Uomini, piante e animali nella dimensione del sacro. Bari: Edipuglia, pp. 71-81.

De Grossi, J. y Minniti, C. (2006): “Dog Sacrifice in the Ancient World: A Ritual Passage?”. En Snyder, L. M. y Moore, E. A. (eds.): Dogs and People in Social, Working, Economic or Symbolic Interaction. Oxford: Oxbow Books, pp. 62-66.

Delibes de Castro, G. (1995): "Ávila, del Neolítico al Bronce”. En Mariné, M. (coord.): Historia de Ávila. I. Prehistoria e Historia. Ávila: Institución Gran Duque de Alba, pp. 21-102.

Driesch, A. von Den (1976): A guide to the measurement of animal bones from Archaeological sites. Harvard: Peabody Museum Bulletin, 1.

Driesch, A. von den y Boessneck, J. (1974): "Kritische Anmerkungen zur Widerristhöhenberechnung aus Längenmassen vor-und frühgeschichtlichen Tierknochen", Säugetierkundliche Mitteilungen, 22, pp. 325-348.

Esparza, Á. (2009): "Recobrando el tiempo perdido: El Bronce Medio y Final en la región de Madrid”, Trabajos de Prehistoria, 66 (1), pp. 185-187.

Esparza, Á.; Delibes de Castro, G.; Ramos, P.; SalvaDOR, M. y Velasco, J. (2008): "Una nueva sepultura del grupo Cogotas I en 'El Juncal' (Villaralbo, Zamora)", Zephyrus, LXI, pp. 155-175.

Esparza, Á.; Velasco, J. y Delibes de Castro, G. (2012): "Exposición de cadáveres en el yacimiento de Tordillos (Aldeaseca de la Frontera, Salamanca). Perspectiva bioarqueológica y posibles implicaciones para el estudio del ritual funerario de Cogotas I", Zephyrus, LXIX, pp. 95-128.

Fabián, F. J. (1995): El aspecto funerario durante el Calcolitico y los inicios de la Edad del Bronce en la Meseta Norte. Acta Salmanticensia, 93. Salamanca: Univ. Salamanca.

García Blánquez, L.; Martínez Sánchez, C. y Ponce García, A. (2003): "Excavaciones en la Glorieta de San Vicente". En XIII Jornadas de Patrimonio Histórico y Arqueología Regional. Murcia, pp. 20-22.

García Lerga, R. L.; Sánchez Seguido, F.; Vicente Navarro, A.; Rojas Martínez-Malo, J. M. y Pérez LópezTriviño, J. (2008): "El yacimiento calcolítico 'Valladares I (р.к. $0+150)$ ' de Illescas (Toledo)”, Arse. Boletín del Centro Arqueológico Saguntino, 42, pp. 127-152.

Gautier, A. (1990): La Domestication. Et l'homme créa l'animal. Paris: Errance.

Gómez Pérez, J. L.; Blasco, C.; Trancho, G.; Ríos, P.; Grueso, I. y Martínez, M. a S. (2011): "Los protagonistas”. En Blasco, C.; Liesau, C. y Ríos, P. (eds.): Yacimientos calcoliticos con Campaniforme de la Región de Madrid: Nuevos estudios. Madrid: UAM, pp. 101-132.

González Fernández, M. a L. (coord.) (2009): El Pelambre (Villaornate, León): el horizonte Cogotas I de la Edad del Bronce y el periodo tardoantiguo en el Valle Medio del Esla. León: Tragsa.
Gräslund, A. S. (2004): "Dogs in graves-a question of symbolism?”. En Santillo, B. (ed.): Pecus. Man and animal in Antiquity. Rome: The Swedish Institute in Rome, pp. 167-176.

Habermehl, K. H. (1974; 2. ${ }^{\text {a }}$ ed.): Die Altersbestimmung bei Haus-und Labortieren. Berlin: Paul Parey Verlag.

Harcourt, R. A. (1974): "The Dog in Prehistoric and Early Historic Britain”, Journal of Archaeological Science, 1, pp. 151-175. http://dx.doi.org/10.1016/0305-4403(74)90040-5

Hernández, L. y Hernández, M. S. (2012): “Cogotas I en la Meseta española”. En Rodríguez Marcos, J. A. y Fernández Manzano, J. (eds.): Cogotas I. Una cultura de la Edad del Bronce en la Península Ibérica. Homenaje a M. ${ }^{a}$ Dolores Fernández-Posse. Valladolid: Univ. Valladolid- JCyL, pp. 187-218.

Horard-Herbin, M. P. (2000): "Dog management and use in the late Iron Age. The evidence from the Gallic site of Levroux (France)". En Crockford, S. J. (ed.): Dogs Through Time: An Archaeological perspective. BAR Int. Ser., 889. Oxford: Archaeopress, pp. 115-121.

Jimeno, A. y Fernández Moreno J. J. (1991): Los Tolmos de Caracena (Soria). Campañas de 1981 y 1982. Aportación al Bronce Medio de la Meseta. EAE, 161. Madrid: Ministerio de Cultura.

KoudelKa, F. (1885): "Das Verhältnis des Ossa longa zur Skeletthöhe bei den Säugethieren", Verhandlungen des Naturforschenden Vereins in Brünn, 24, 127-153

Lapham, H. A. (2010): "A Baumer Phase Dog Burial from the Kincaid Site in Southern Illinois", Illinois Archaeology, 22 (2), pp. 437-463.

LARsSON, L. (1991): "Symbolism and mortuary practice. Dogs in fractions-symbols in action", Archaeology and Environment, 11, pp. 33-38.

LARsson, L. (1994): "Pratiques mortuaires et sépultures de chiens dans les sociétés mésolithiques de Scandinavie méridionale", L'Anthropologie, 98 (4), pp. 562-575.

LIÉNARD, P. (2006): “The making of peculiar artifacts: Living kind, artifact and social order in the Turkana sacrifice", Journal of Cognition and Culture, 6 (3/4), pp. 343-373.

http://dx.doi.org/10.1163/156853706778554940

Liesau, C. (1998): "El Soto de Medinilla: Faunas de mamíferos de la Edad del Hierro en el valle Medio del Duero (Valladolid, Espańa)", Archaeofauna, 7, pp. 7-210.

Liesau, C. (2012): "Depósitos con ofrendas de animales en yacimientos Cogotas I: antecedentes y características". En Rodríguez Marcos, J. A. y Fernández ManZANo, J. (eds.): Cogotas I. Una cultura de la Edad del Bronce en la Península Ibérica. Homenaje a M.a Dolores Fernández-Posse. Valladolid: Univ. de Valladolid-JcyL, pp. 219-257. 
Liesau, C. y Blasco, M. ${ }^{a}$ C. (2006): "Depósitos con fauna en yacimientos del Bronce Medio en la Cuenca del Tajo". En Bicho, N. F. (ed.): Animais na Pré-história e Arqueologia da Peninsula Ibérica. Actas do IV Congresso de Arqueologia Peninsular (Faro 2004). Faro: Univ. Algarve, pp. 81-92.

Liesau, C.; Blasco, M. a C.; Blanco, J. F.; Ríos, P.; Vega, J.; Menduiña, R. C.; Baena, J.; Herrera, T.; Petri, A. y Gómez, J. L. (2008): “Un espacio compartido por vivos y muertos: el poblado calcolítico de fosos de Camino de las Yeseras", Complutum, 19 (1), pp. 97- 120.

Liesau, C.; García García, J.; Carrión, E. y Blasco, M. ${ }^{a}$ C. (2004): "El depósito ritual del fondo 76-78 de la Fábrica de Ladrillos (Getafe, Madrid)", Cuadernos de Prehistoria y Arqueología de la Universidad Autónoma de Madrid, 30, pp. 47-56.

Lizcano, R.; Cámara, J. A.; Riquelme, J. A.; Afonso, J. A.; Cañabate, L. y Sánchez, A. (1991-92): "El polideportivo de Martos. Producción económica y símbolos de cohesión en un asentamiento del Neolítico Final en las campiñas del Alto Guadalquivir”, Cuadernos de Prehistoria de la Universidad de Granada, 16-17, pp. 5-101.

Lomba, J.; López, M.; Ramos, F. y Avilés, A. (2009): “El enterramiento múltiple, calcolítico, de Camino del Molino (Caravaca, Murcia). Metodología y primeros resultados de un yacimiento excepcional", Trabajos de Prehistoria, 66 (2), pp. 143-159.

http://dx.doi.org/10.3989/tp.2009.09025

López Covacho, L.; Ortiz del Cueto, J. R. y RodríGuez y Fuente, M. (1996): "El yacimiento prehistórico de Pedazo del Muerto (Pinto, Madrid)". Actas de la Reunión de Arqueología Madrileña. Madrid: pp. 181-186.

Losey, R. J.; Bazalissii, V. I.; Garvie-Lok, S.; Germonpré, M; Leonard, J. A.; Allen, A. L.; Katzenberg, M. A. y Sablin, M. V. (2011): "Canids as persons: Early Neolithic dog and wolf burials, Cis-Baikal, Siberia", Journal of Anthropological Archaeology, 30, pp. 174-189. http://dx.doi.org/10.1016/j.jaa.2011.01.001

Lupo, K. D. y JANETSKI, J. C. (1994): "Evidence of Domesticated Dogs and Some Related Canids in the Eastern Great Basin", Journal of California and Great Basin Anthropology, 16 (2), pp. 199-220.

Manhart, H.; Driesch, A. von den y Liesau, C. (2000): "Investigaciones zooarqueológicas en Fuente Álamo". En Schubart, H.; Pingel, V. y Arteaga, O.: Fuente Álamo. Las excavaciones arqueológicas 1977-1991 en el poblado de la Edad del Bronce. Sevilla: Junta de Andalucía, pp. 223-240.

Márquez, J. (2006): “Sobre los depósitos estructurados de animales en yacimientos de fosos del Sur de la Península
Ibérica”. En Bicho, N. F. (ed.): Animais na Pré-história e Arqueologia da Península Ibérica. Actas do IV Congresso de Arqueologia Peninsular (Faro 2004). Faro: Univ. do Algarve, pp. 15-25

Masson, O. (1950): “A propos d'un rituel hittite pour la lustration d'une armée: le rite de purification par le passage entre les deux parties d'une victime", Revue de l'histoire des religions, 137 (1), pp. 5-25.

http://dx.doi.org/10.3406/rhr.1950.5699

Misiego, J. C.; Pérez Rodríguez, F. J.; Sanz García, F. J.; Marcos Contreras, G. J. y Martín Carbajo, M. A. (1992): "La Huelga. Bronce Medio en la Meseta Norte", Revista de Arqueología, 136, pp. 18-25.

Morales, A. y Liesau, C. (1995): "Análisis comparado de las faunas arqueológicas en el valle Medio del Duero (Prov. Valladolid) durante la Edad del Hierro". En DElibes, G.; Romero, F. y Morales, A. (eds.): Arqueología y Medio Ambiente. El Primer Milenio a.C. en el Duero Medio. Valladolid: JCyL, pp. 455-514.

Morris, J. (2008): "Associated bone groups; one archaeologist's rubbish is another's ritual deposition". En DAVIs, O.; Sharples, N. y Waddington, K. (eds.): Changing perspectives on the First Millenium BC. Oxford: Oxbow, pp. 83-98.

Morris, J. (2011): Investigating Animal Burials: Ritual, Mundane and Beyond. BAR Int. Ser., 535. Oxford: Oxbow.

Palomino, A. L.; Negredo, M. J. y Abarquero, F. J. (1999): “Cabañas, basureros, silos y tumbas en el yacimiento de El Cerro, La Horra (Burgos): a vueltas sobre el significado de un campo de hoyos en la Edad del Bronce de la Meseta", Numantia. Arqueología en Castilla y León, 7, pp. 21-41.

Pérez Rodríguez, F. J.; Misiego, J. C.; Sanz García, F. J.; Marcos Contreras, G. J.; Martín Carbajo, M. A. y Fernández Giménez, J. M. (1994): “La Huelga': un interesante yacimiento de la Edad del Bronce en el centro de la Cuenca del Duero (Dueñas, Palencia)", Numantia. Arqueología en Castilla y León, 5, pp. 11-32 .

Ramos, M. (2009): "Arqueología en la Autovía del Camino", Trabajos de Arqueología de Navarra, 21, pp. 5-121.

Rodríguez Marcos, J. A. (2008): Estudio secuencial de la Edad del Bronce en la Ribera del Duero (Provincia de Valladolid). Monografías. Arqueología en Castilla y León, 7. Valladolid: JCyL.

SÁnchez Polo, A. (2010): "La muerte en la arqueología: visiones cruzadas/posiciones encontradas”, El Futuro del Pasado. Revista Electrónica de Historia, 1, pp. 173-187 [http://www.elfuturodelpasado.com/elfuturodelpasado/eFdP_1.html].

SÁnchez Polo, A. (2012): "Depósitos de cerámicas, molinos y elementos de hoz: una propuesta de la Edad 
del Bronce del interior peninsular desde la arqueología posprocesual", Arkeogazte. Revista de Arqueología, 2, pp. 73-93. [http://www.arkeogazte.org].

Sanchís, A. y Sarrión, I. (2004): "Restos de cánidos (Canis familiaris ssp.) en yacimientos valencianos de la Edad del Bronce", Archivo de Prehistoria Levantina, 25, pp. 161-198.

Sergis, M. G. (2010): "Dog Sacrifice in Ancient and Modern Greece: From the Sacrifice Ritual to Dog Torture (kynomartyrion)", Folklore. Electronic Journal of Folklore, 45, pp. 61-88. http://dx.doi.org/10.7592/FEJF2010.45.sergis

Serpell, J. (ed.) (1995a): The domestic dog: its evolution, behavion and interactions with people. Cambridge: CuP, pp. 80-102.

Serpell, J. (1995b): “Introduction”. En Serpell, J. (ed.): The domestic dog: its evolution, behavior, and interactions with people. Cambridge: cup, pp. 1-4.

Serpell, J. (1995c): "From paragon to pariah: some reflections on human attitudes to dogs". En Serpell, J. (ed.): The domestic dog: its evolution, behavior, and interactions with people. Cambridge: cup, pp. 246-256.

Serpell, J. y Jagoe, J. A. (1995): "Early experience and the development of behavior". En Serpell, J. (ed.): The domestic dog: its evolution, behavior, and interactions with people. Cambridge: cup, pp. 80-102.
Trantalidou, K. (2006): “Companions from the Oldest Times: Dogs in Ancient Greek Literature, Iconography and Osteological Testimony". En SNYDer, L. M. y Moore, E. A. (eds.): Dogs and People in Social, Working, Economic or Symbolic Interaction. Oxford: Oxbow Books, pp. 96-119.

Valera, A. C.; Nunes, T. y Costa, C. (2010): "Enterramentos de canídeos no Neolítico: A fossa 5 de Corça 1 (Brinches, Serpa)", Apontamentos de Arqueologia e Património, 5, pp. 7-17.

Valiente, J. (1992): La Loma del Lomo II (Cogolludo, Guadalajara). Toledo: Junta de Comunidades de Castilla la Mancha.

Vega, L. G.; Cerdeño, M. a L. y Córdoba, B. (1998): "El origen de los mastines ibéricos. La trashumancia entre los pueblos prerromanos de la Meseta", Complutum, 9, pp. 117-135.

Verdú, J. C. (2004): "Excavación 'Marianela', Lorca”. En XV Jornadas de Patrimonio Histórico y Arqueología de la Región de Murcia. Murcia: Consejería de Educación y Cultura, pp. 31-33.

Wilkens, B. (2006): "Sacrifice of Dogs in Ancient Italy". En Snyder, L. M. y Moore, E. A. (eds.): Dogs and People in Social, Working, Economic or Symbolic Interaction. Oxford: Oxbow Books, pp. 131-136. 